Canadian

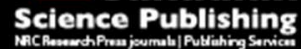

Canadian Journal of Microbiology Revue canadienne de de microbiologie

\title{
The Sclerotinia sclerotiorum Slt2 mitogen-activated protein kinase ortholog, SMK3, is required for infection initiation, but not lesion expansion
}

\begin{tabular}{|r|l|}
\hline Journal: & Canadian Journal of Microbiology \\
\hline Manuscript ID & cjm-2016-0091.R2 \\
\hline Manuscript Type: & Article \\
\hline Complete List of Authors: & $\begin{array}{l}\text { Bashi, Zafer; University of Saskatchewan, } \\
\text { Gyawali, Sanjaya; } \\
\text { Bekkaoui , Diana; Agriculture and Agri-Food Canada, } \\
\text { Coutu, Cathy ; AAFC } \\
\text { Lee, Leora ; AAFC } \\
\text { Poon, Jenny ; AAFC } \\
\text { Rimmer, S. Roger; AAFC } \\
\text { Khachatourians, George; University of Saskatchewan } \\
\text { Hegedus, Dwayne; AAFC, }\end{array}$ \\
\hline Keyword: & $\begin{array}{l}\text { Sclerotinia sclerotiorum, mitogen activated protein kinase, infection, cell } \\
\text { wall integrity }\end{array}$ \\
\hline &
\end{tabular}


1 The Sclerotinia sclerotiorum S/t2 mitogen-activated protein kinase ortholog, SMK3, is required 2 for infection initiation, but not lesion expansion

3

4 Zafer Dallal Bashi ${ }^{1,2}$, Sanjaya Gyawali ${ }^{1}$, Diana Bekkaoui ${ }^{1}$, Cathy Coutu ${ }^{1}$, Leora Lee ${ }^{1}$, Jenny Poon ${ }^{1}$, 5 S. Roger Rimmer ${ }^{1}$, George G. Khachatourians ${ }^{2}$, and Dwayne D. Hegedus ${ }^{1,2}$

$6{ }^{1}$ Agriculture and Agri-Food Canada, 107 Science Place Saskatoon, SK, Canada, S7N OX2;

$7{ }^{2}$ Department of Food and Bioproduct Sciences, University of Saskatchewan, Saskatoon,

8 SK, Canada, S7N 5A8

10 Corresponding author:

11 Dwayne Hegedus

12 Agriculture and Agri-Food Canada,

13107 Science Place, Saskatoon, SK, Canada, S7N OX2

14 Telephone: 306-956-7667

15 Fax: 306-956-7247

16 E-mail: hegedusd@agr.agr.ca

17

18 Other author contact information:

19 Sanjaya Gyawali - gyawalisanjaya@gmail.com

20 Diana Bekkaoui - Diana.Bekkaoui@agr.gc.ca

21 Cathy Coutu - Cathy.Coutu@agr.gc.ca

22 Leora Lee - lee.leora@gmail.com

23 Jenny Poon - jenny-poon@hotmail.com

24 George Khachatourians - george.khachatourians@usask.ca

25 S. Roger Rimmer - deceased (Dwayne.Hegedus@sasktel.net) 


\section{Abstract}

27 Mitogen activated protein kinases (MAPKs) play a central role in transferring signals and

28 regulating gene expression in response to extracellular stimuli. An ortholog of the Saccharomyces

29 cerevisiae cell wall integrity MAPK was identified in the phytopathogenic fungus Sclerotinia

30 sclerotiorum. Disruption of the S. sclerotiorum Smk3 gene severely reduced virulence on intact

31 host plant leaves, but not on leaves stripped of cuticle wax. This was attributed to alterations in

32 hyphal apical dominance leading to the inability to aggregate and form infection cushions. The

33 mutation also caused loss of the ability to produce sclerotia, increased aerial hyphae formation,

34 altered hyphal hydrophobicity and cell wall integrity. Mutants had slower radial expansion rates

35 on solid media, but more tolerant to elevated temperatures. Loss of the SMK3 cell wall integrity

36 MAPK appears to have impaired the ability of S. sclerotiorum to sense its surrounding

37 environment leading to misregulation of a variety of functions. Many of the phenotypes were

38 similar to those observed in S. sclerotiorum adenylate cylase and SMK1 MAPK mutants suggesting

39 that these signalling pathways interact to co-regulate aspects of fungal growth, physiology and

40 pathogenicity.

43 Key Words

45 Sclerotinia sclerotiorum, mitogen activated protein kinase, infection, cell wall integrity. 


\section{Introduction}

Sclerotinia sclerotiorum is an aggressive, cosmopolitan plant pathogen that infects over 400 different species (Boland and Hall 1994). Though able to germinate on the host cuticle surface, $S$. sclerotiorum ascospores are generally unable to directly infect many hosts (Lumsden 1979). Often, senescent materials, such as shed petals lodged in the axis between the main stem and branch as in Brassica napus, provide a source of water and nutrients to generate sufficient mycelial biomass to initiate infection (Abawi et al. 1975; Lumsden and Dow 1973). Upon contact with the host, mycelia form finger-like appendages that develop into multi-celled, dome-shaped structures referred to as infection cushions (Abawi et al. 1975). Following cuticle penetration, a short biotrophic phase allows the pathogen to establish within the host (Kabbage et al. 2015). Mycelia then ramify throughout host tissue, assisted by the release of hydrolytic enzymes (Martel et al. 1996; Poussereau et al. 2001a, b; Kasza et al. 2004; Li et al. 2004; Bashi et al. 2012; Zhang et al. 2014), oxalic acid (Godoy et al. 1990) and necrosis-inducing proteins (Bashi et al. 2010a; Bashi et al. 2013). Consumption of necrotic host tissue provides the resources needed for sclerotial development and completion of the life cycle. The transition between these phases is determined by numerous signals, including contact with hard surfaces (Bashi et al. 2012), glucose levels (Vautard-Mey et al. 1999), cAMP levels (Rollins and Dickman 1998; Girard et al. 2004; Jurick and Rollins 2007), ambient pH (Rollins and Dickman 2001; Cotton et al. 2003; Rollins 2003; Favoron et al. 2004), and oxidative stress (Kim et al. 2011; Papapostolou et al. 2014). Furthermore, coordination of these signaling pathways may involve various protein kinases (Vautard-Mey and Fevre 2000; Vacher et al. 2003; Chen et al. 2004; 2005; Jurick et al. 2004; Harel et al. 2005; Erental et al. 2008; Bashi et al. 2010b; Duan et al. 2013) and phosphatases (Harel et al. 2006; Erental et al. 2007). An increasing number of extra-cellular effectors have also been shown to affect host-pathogen interactions and disease progression (Liang et al. 2013; Zhu et al. 2013; Guyon et al. 2014; Xiao et al. 2014; Zhang et al. 2014; Lyu et al. 2015, 2016; Pan et al. 2015).

Extracellular-signal-regulated kinases (ERKs), also known as classical mitogen-activated protein kinases (MAPK), are components of pathways that transfer signals from the external environment to the nucleus. Such signals initiate a cascade of phosphorylation events that eventually impact the transcription control apparatus. MAPK are activated by phosphorylation by upstream MAPK kinases. Five main MAPK pathways have been characterized in Saccharomyces cerevisiae; these are described as the mating pheromone response pathway, the filamentation-invasion pathway, 
the spore wall assembly pathway, the high osmotic growth pathway and the cell wall integrity pathway (Gustin et al. 1998). MAPK pathways with orthologous elements also exist in many fungal pathogens, though in some cases they have evolved to regulate different biological processes (Xu 2000). For example, MAPKs encoded by the orthologs of S. cerevisiae Fus3 (pheromone) and Kss1 (filamentation-invasion) genes, including Botrytis cinerea BMP1 (Zheng et al. 2000), Cochliobolus heterostrophus CHK1 (Lev et al. 1999), Colletotrichum lagenarium CMK1 (Takano et al. 2000), Fusarium oxysporum FMK1 (Di Pietro et al. 2001), Fusarium verticillioides FvMK1 (Zhang et al., 2011), and Ustilago maydis UBC3 (Mayorga and Gold 1999), are essential for pathogenesis and are referred to as pathogenicity MAPKs. In S. sclerotiorum, the KSS1-related MAPK, SMK1, was also found to play a central role in coordinating signals from $\mathrm{pH}, \mathrm{cAMP}$ and oxalic acid during the formation of sclerotia (Chen et al. 2004).

The S. sclerotiorum orthologs of the S. cerevisiae MAPK associated with the cell wall integrity pathway, SLT2, have also been identified in several pathogenic yeasts and filamentous fungi, including S. sclerotiorum (Hegedus et al. 2015). S/t2 ortholog MAPK mutants frequently have an osmotic-remediable lytic phenotype caused by impaired cell wall biogenesis (De Nobel 2000; Levin 2005). In Candida albicans, MKC1 has been shown to be essential in sensing contact with surfaces and transitioning to invasive growth (Kumamoto 2005). The Mkc1 mutant was unable to form filamentous invasive hyphae and was non-pathogenic. In addition, the mutant had increased sensitivity to cell wall degrading enzymes suggesting that cell wall architecture was altered (Navarro-Garcia et al. 1995). Mutation of Mps1 in Magnaporthe grisea caused a range of changes in physiological functions including reduced aerial hyphae growth and conidiation. Colonies also exhibited central progressive autolysis that was recoverable with the addition of $1 \mathrm{M}$ sorbitol to the medium, indicating a deficiency in osmotolerance. Similar to the C. albicans mkc1 mutant, the M. grisea Mps1 mutant was also more susceptible to treatment with cell wall degrading enzymes and was avirulent (Xu et al. 1998). In Fusarium graminearum, mutation of MGV1 caused reduced growth on solid medium as well as reduced aerial hyphae formation and conidiation. Mutant colonies also had reduced pigmentation indicating that secondary metabolism was also affected. Similar to those above, this mutant was more susceptible to cell wall degrading enzymes and high temperatures and was less virulent. Interestingly, the mutant was found to be only male fertile with reduced hyphal fusion and heterokaryon formation (Hou et al. 2002). 
110 In B. cinerea, a close relative of S. sclerotiorum, mutation of the SIt2 ortholog Bmp3, caused a

111 severe reduction in aerial hyphae formation and conidiation (Rui and Hahn 2007) similar to the $F$.

112 graminearum MGV1 mutant. Generally, radial expansion of mutant colonies was slower than the

113 wild type and supplementation with nutrients failed to recover the phenotype. Unlike previously

114 characterized mutants in other filamentous fungi, the $B$. cinerea mutant did not exhibit heat

115 sensitivity or susceptibility to cell wall degrading enzymes. Conidial germination was unaffected;

116 however, germ tubes elongated excessively and were unable to penetrate the host. Hyphae also

117 exhibited reduced epidermal cell penetration and fewer lesions formed on intact leaves, though

118 pathogenicity was impacted to a lesser extent on wounded leaves where the cuticle had been

119 damaged (Rui and Hahn 2007). These observations clearly demonstrate that the cell wall integrity

120 MAPK pathway controls diverse physiological functions and is important for pathogenicity;

121 however, different aspects of the infection process are involved dependent upon the pathogen,

122 its lifestyle and the host.

123

124 In this study, the S. sclerotiorum S/t2 ortholog, Smk3, was characterized and a wide range of

125 primary and secondary effects were caused by its disruption. Most importantly, SMK3 was found

126 to be required for sclerotia formation as well as initiation of infection, but not subsequent

127 proliferation within host tissues.

128 
129 Materials and Methods

130 Fungal strains

131 Sclerotinia sclerotiorum strain 1980 (ATCC18683) was used throughout this study. The generation

132 and selection of homokaryotic Smk3v disruption mutant lines derived from 1980 has been

133 described previously (Bashi et al. 2010b) and were cultured under the same conditions.

134

135

A line was also generated in which the threonine and tyrosine residues in the TEY motif of SMK3 that are phosphorylated during MAPK activation were substituted for aspartic acid in an attempt to create a constitutively active form of SMK3. The modified Smk3 gene, denoted $S m k 3 u^{D E D}$ for aspartic acid (D)-glutamic acid (E)-aspartic acid (D), was generated using SOEing PCR (Horton et al. 1990 ) as follows. The first SOEing PCR fragment was generated by amplifying genomic DNA with MKCgenF (5'-GAAGGGTTCATTTCGAGCCGAG-3') and MKCsoeingR (5'GCAACATCTTCATCCATGTATCCAGCATTCTCTTCAGGATC-3'), and the second fragment with MKCsoeingF (5' - GCTGGATACATGGATGAAGATGTTGCTACAAGATGGTACCGTGCC-3') and MKCgenR (5'- AAAATCCCAAAGCCTCTAAACACCG-3'). The mutated regions are located within the overlapping SOEing primers and are underlined. The fragments were assembled in a second PCR by first extending the annealed overlapping fragments for 5 PCR cycles followed by amplification of the entire assembled region using the MKCgenF and MKCgenR primers. The ca. 5000 bp Smk3 region was cloned into pBARKS (Fungal Genetics Stock Center, www.fgsc.net) and sequenced. The fungal transformation construct was prepared as follows. A $1549 \mathrm{bp}$ fragment of the mutated Smk3 gene was amplified with primers MCK1 ca F 2565 Sal I (5'GTCGACGTAAGAAGATTTTGGCAAAGC-3') located between exon 2 and exon 3512 bp upstream of mutation sit) and MKC1 ca R term 4085 (5'-TTCGCTGTTGCATTGCTATAGG-3') which overlaps the stop codon. The hygromycin resistance cassette was amplified from pCB1004 (Fungal Genetics Stock Center) using Hyg pCB1004 F (5'-AACTGGTTCCCGGTCGGCATC-3') and Hyg pCB1004 R (5'AACTGATATTGAAGGAGC-3'). A 355 bp Smk3 3'untranslated region (UTR) was amplified using MKC1 3' F amp Pstl (5'-CTGCAGTTTGTGTATTGTCTTGTATCG-3') and MKC1 3' R amp 4509 Notl (5'GCGGCCGCGTGATTAAAATCCCAAAGCC-3'). All fragments were cloned into pGEM T-Easy

157 (Promega) and sequenced. The mutated Smk3 fragment was excised by digestion with Sall and

158 EcoRI and cloned into pBluescriptKS (Promega). The hygromycin cassette was released by

159 digestion with EcoRI and Pstl and inserted downstream of the mutated Smk3 gene. The Smk3 3'UTR was released by digestion with Pstl and Notl and inserted downstream of the hygromycin 
161 cassette. This configuration allows replacement of the wild type Smk3 gene with the modified

162 allele and selectable marker by homologous recombination. The construct was released by

163 digestion with Sall and SstI and cloned into pCB301 for Agrobacterium-mediated transformation

164 of S. sclerotiorum 1980 mycelia as described previously (Bashi et al. 2010b). Accurate

165 replacement of the endogenous $S M K 3$ gene with the $S m k 3 u^{D E D}$ allele was verified by amplification

166 of the locus followed by sequencing. Homokaryotic lines were selected as previously described

167 (Bashi et al. 2010b).

168

169

170

\section{Effect of contact surface on MAPK phosphorylation and gene expression}

To examine MAPK phosphorylation in response to contact with various solid surfaces, $S$. sclerotiorum strain 1980 was grown on potato dextrose agar (PDA) at $20^{\circ} \mathrm{C}$. Thirty plugs, $3 \mathrm{~mm}$ in diameter, were excised from the advancing margin of the colony and used to inoculate $200 \mathrm{~mL}$ of minimal salts-glucose (MS-Glu) medium (10 g/L glucose, $2 \mathrm{~g} / \mathrm{L} \mathrm{NH}_{4} \mathrm{NO}_{3}, 1 \mathrm{~g} / \mathrm{L} \mathrm{KH}_{2} \mathrm{PO}_{4}, 0.1 \mathrm{~g} / \mathrm{L}$ $\mathrm{MgSO}_{4} 7 \mathrm{H}_{2} \mathrm{O}, 0.5 \mathrm{~g} / \mathrm{L}$ yeast extract, $3 \mathrm{~g} / \mathrm{L} \mathrm{DL}$-malic acid, $1 \mathrm{~g} / \mathrm{L} \mathrm{NaOH}$ ). The culture was incubated at $20^{\circ} \mathrm{C}$ in a $1 \mathrm{~L}$ flask with shaking at $80 \mathrm{rpm}$ for 3 days. Mycelia were then harvested by centrifugation at 10,000 rpm and placed on glass slides, glass slides coated with leaf cuticle wax, Parafilm, or $B$. napus cv. Westar leaves. Leaf wax was isolated by dipping $B$. napus leaves in chloroform for $30 \mathrm{sec}$ and evaporating the chloroform under a stream of liquid nitrogen. Wax was applied by dissolving the crystals in a small volume of chloroform, spreading it to form a thin film on a glass Petri dish and allowing the chloroform to evaporate. Mycelia were incubated in contact with the various surfaces for $10 \mathrm{~min}$ at $20^{\circ} \mathrm{C}$ and then immediately frozen in liquid nitrogen. Total protein was extracted by grinding the mycelia in liquid nitrogen and incubating in extraction buffer (10 mM Tris-HCl pH 8.0, 1 mM EDTA, 2\% DTT) at a 1:5 w/v ratio for $2 \mathrm{~min}$. Samples were then centrifuged at $14,000 \mathrm{rpm}$ for $5 \mathrm{~min}$ in a micro-centrifuge and the supernatant transferred to a separate tube and stored at $-20^{\circ} \mathrm{C}$. Western blot analysis was conducted using a commercially available antibody that can specifically detect phosphorylated ERK1/ERK2 type MAPKs (Cell Signaling Technology). Western blot analysis was conducted according to the manufacturer's protocol.

The effect of contact surface and carbon availability on Smk1 and Smk3 gene expression was examined as follows. Mycelia grown as above were spread onto intact $B$. napus leaves or leaves that had been stripped of wax by dipping in chloroform for $30 \mathrm{sec}$ and then allowing the 
193

194

195

196

197

198

199

200

201

202

203

204

205

206

207

208

209

210

211

212

213

214

215

216

217

218

219

220

221

222

chloroform to evaporate. The leaves were incubated for $24 \mathrm{~h}$ on wet filter paper in a sealed plastic container with moistened Whatman No. 5 filter paper to provide adequate humidity for infection. The mycelial mat was removed with a forceps and then immediately frozen in liquid nitrogen. Northern blot analysis was conducted as described earlier (Bashi et al. 2010a). DNA fragments corresponding to Smk1 and Smk3 were amplified from S. sclerotiorum genomic DNA and used as probes. The following primers were used: Smk1 forward (5'-CTTCTCGCATTTAATCCTG-3') and Smk1 reverse (5'-CCTTGGTGAGGTTGTCC-3') and Smk3 forward (5'-CTTCTCGCATTTAATCCTG-3') and Smk3 reverse (5'- CCTTGGTGAGGTTGTCC-3').

\section{Microscopy}

A plug from the growing margin of a colony was used to inoculate a PDA plate which was then incubated at $20^{\circ} \mathrm{C}$ for 3 days. To examine aerial hyphae formation, vertical sections were made through the colony using a razor and a $1 \mathrm{~mm}$ thick slice laid on a glass slide. Samples were examined at $20 \mathrm{X}$ magnification using a dissecting microscope. To determine the branching pattern, mycelia were cultivated in MS-Glu liquid medium and examined using a light microscope at $200 \mathrm{X}$ magnification.

\section{Incubation in cell wall degrading enzyme cocktail}

Mycelia were grown in $25 \mathrm{~mL}$ of potato dextrose broth for 3 days at $20^{\circ} \mathrm{C}$ and washed once with sterile water and once with buffer $\left(0.8 \mathrm{M} \mathrm{MgSO}_{4} 7 \mathrm{H}_{2} \mathrm{O}, 0.2 \mathrm{M}\right.$ sodium citrate, $\left.\mathrm{pH} 5.5\right)$. Mycelia were then coarsely fragmented with a razor and incubated in $10 \mathrm{mg} / \mathrm{mL}$ Trichoderma harzianum Lyase (Sigma-Aldrich) in buffer (1 M sorbitol, $50 \mathrm{mM}$ sodium citrate, $\mathrm{pH}$ 5.8). The mixture was incubated at $28^{\circ} \mathrm{C}$ with shaking at $100 \mathrm{rpm}$. Samples were collected every $30 \mathrm{~min}$ and observed using a light microscope. Protoplasts were counted using a hemocytometer with 4 replicates at each time point for each line. The data was normalized to 1 gram of tissue prior to analysis. Average and standard deviations were calculated for each line at each time point. Differences between the means at each of the four time points $(30,60,90$ and 120 minutes) were analyzed using the General Liner Model (GLM) followed by Tukey's least significant test at a significance level of $0.05 \%$. Data analysis was done using SAS Enterprise version 5.1. 
224 Mycelia hydrophobicity was determined as per Chau et al. (2009). Briefly, microscope slides were sterilized using $70 \%$ ethanol, transferred to a sterile Petri dish and allowed to dry in a sterile flow chamber. Liquid PDA at $37^{\circ} \mathrm{C}$ was poured onto the slide to form $1 \mathrm{~mm}$ thick layer and the media allowed to solidify at room temperature. Using tweezers, a pin head size portion of mycelia was transferred to the edge of the slide and incubated at $20^{\circ} \mathrm{C}$ for 2 days. Water droplets $(10 \mu \mathrm{L})$ were gently placed on the mycelia and analyzed immediately. Droplet images were analyzed using ImageJ (http://rsb.info.nih.gov/ij/) and a plug-in for the analysis of drop shape used to measure the contact angle (http://bigwww.epfl.ch/demo/dropanalysis). Measurements were taken from two locations, the edge and the center of the colony, with three replications for each line. Differences between means for the edge and center locations were determined for each line using the Student T-test at a significance level of $0.05 \%$. Analysis of the means at each of the two locations over the three lines was analyzed using General Liner Model (GLM) followed by Tukey's least significant test at a significance level of $0.05 \%$. Data analysis was done using SAS Enterprise version 5.1 .

\section{Effect of temperature and compounds that affect cell wall integrity on growth}

To assess the effect of temperature on growth, PDA was inoculated using a $3 \mathrm{~mm}$ plug from the edge of a growing colony. The plates were incubated at $20,28,37$ and $52^{\circ} \mathrm{C}$ and colony diameters measured daily. The ratio of growth at $28^{\circ} \mathrm{C}$ to that at $20^{\circ} \mathrm{C}$ was calculated from three independent replicates. This calculation was used to account for the difference in colony expansion rate between the wild type and the mutants and measures the change in expansion ratio.

Radial expansion was also assessed on PDA supplemented with compounds that affect growth of yeast and fungal mutants with altered cell wall integrity including $1.5 \mathrm{M}$ glucose, $1.5 \mathrm{M}$ sorbitol, 1 $\mathrm{M} \mathrm{KCl}, 1 \mathrm{M} \mathrm{NaCl}, 300$ uM Congo Red, $1.5 \mathrm{mM}$ Calcofluor White, 0.01\% SDS and $10 \mathrm{mM}$ caffeine. Colony diameter was measured daily on each of four independent replicates.

\section{Pathogenicity assay and infection cushion examination}


255 chloroform for $30 \mathrm{sec}$ and then allowing the chloroform to evaporate. The leaves were incubated 256 on wet Whatman No. 5 paper for $24 \mathrm{~h}$ in a sealed plastic container. To observe infection cushion 257 development, $20 \mu \mathrm{L}$ MS-Glu media droplets containing a mycelial suspension were applied to the 258 leaf surface and allowed to incubate for $24 \mathrm{~h}$ under the same conditions as the pathogenicity 259 assay above.

260 
261 Results

262 Changes in MAPK phosphorylation in response to contact with different surfaces

263 To better understand the role of MAPKs in sensing contact with a surface, S. sclerotiorum mycelia

264 were applied to different solid surfaces including leaf wax, glass, Parafilm, and leaves for $10 \mathrm{~min}$.

265 Western blot analysis of total cell protein from these mycelia with an anti-phospho ERK1/ERK2

266 type MAPK antibody revealed that phosphorylation of ERK1/ERK2 type MAPKs increased upon

267 contact of mycelia with a solid surface. The patterns and levels of MAPK phosphorylation were

268 similar after contact with all the solid surfaces tested (Figure 1).

269

270

Characterization of S. sclerotiorum pathogenicity and cell wall integrity MAPKs

271 The western blot analysis above demonstrated that changes in MAPK phosphorylation accompany

272 contact with solid surfaces as would occur during the initial stages of infection. We focused our

273 efforts on the SLT-2 like MAPK involved in the cell wall integrity pathway in S. cerevisiae. A search

274 of the $S$. sclerotiorum genome using BLAST with the $B$. cinerea cell wall integrity MAPK Bmp3

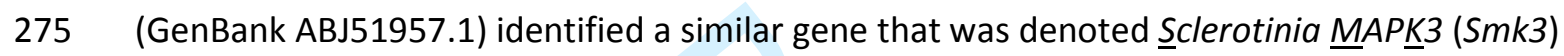

276 (SS1G_05445; GenBank XP_001594017.1). The Smk3 gene was predicted to have 4 introns and 5

277 exons resulting in an open reading frame encoding a protein of 413 amino acids and a molecular

278 mass of $47 \mathrm{kDa}$ as determined by the sum of the component amino acids. SMK3 was most similar

279 to B. cinerea BMP3 (99.8\% identity) and possessed each of the 11 conserved subdomains in the

280 ATP binding and peptide binding/phosphotransfer lobes (Hanks 2003). The functionality of the

281 SMK3 MAPK was asserted by the presence of the conserved TEY motif upstream of subdomain VIII

282 (Figure 2) in which the threonine and tyrosine are phosphorylated leading to activation of the

283 kinase. The published assembly of the S. sclerotiorum genome (Amselem et al. 2011) is missing

284 information $5^{\prime}$ and $3^{\prime}$ to the Smk3 region encoding the open reading frame. We obtained this

285 information during the construction of the transformation vectors and the complete Smk3

286 genomic region has been deposited in GenBank (Accession \# 1891783). A phylogenetic analysis of

287 the S. sclerotiorum protein kinase superfamily, including the MAPK group, can be found in

288 Hegedus et al. (2015).

289

290 Northern blot analysis was used to examine changes in the expression of Smk3 and the

291 pathogenicity MAPK Smk1 in response to contact with different surfaces in the presence or

292 absence of glucose. Glucose was included to simulate the presence of organic carbon that would 
293 be available from senescent plant materials. Smk1 transcript levels did not change when mycelia

294 growing in liquid culture were transferred to intact leaves or leaves stripped of surface wax

295 (Figure 3). The presence of glucose reduced the expression of Smk1 under these conditions,

296 indicating that it may be subject to catabolite repression. Conversely, Smk3 expression was

297 induced on intact leaves in the presence of glucose, which simulates the conditions present during

298 infection. Finally, expression was unaffected on leaves stripped of wax indicating the importance

299 of natural conditions or context for regulation of Smk3 expression.

300

301 Mycelial morphology and sclerotia formation

302 To determine the roles of SMK3 in S. sclerotiorum development, Smk3 disruption mutants (Smk3v

303.3 and Smk3v .5) developed previously by Bashi et al. (2010b) were characterized. In this study,

304 an attempt was made to create a S. sclerotiorum line expressing a constitutively active form of

305 SMK3 by replacing the threonine and tyrosine residues in the TEY motif with aspartic acid, an acid

306 amino acid that has been shown to mimic phosphorylation and lead to constitutive activation of

307 some other kinases. This line was denoted $S m k 3 u^{D E D}$. The phenotypes of the two independent

$308 S m k 3 v$ disruption mutants and the $S m k 3 u^{D E D}$ mutant were found to be nearly identical (see

309 below) indicating the alterations to the TEY motif may have inactivated, rather than activated, the

310 SMK3 kinase.

311

312 Disruption of the S. sclerotiorum Smk1 MAPK gene was found to impair the signaling pathway

313 involved in sclerotia formation (Chen et al. 2004). Similarly, while the wild type strain 1980

314 formed sclerotia within a week of inoculation on solid MS-Glu medium, the Smk3v mutants failed

315 to form sclerotia even after 3 weeks of incubation (Figure 4).

316

317 In liquid culture, both wild type and $S m k 3 v$ mutant mycelia formed spherical aggregates. At the

318 edge of these aggregates, wild type hyphae radiated or projected outward, whereas Smk3v

319 mutant hyphae branched more frequently and closer to the growing tip which increased

320 aggregate density (Figure 4). Microscopic examination of a vertical section of a colony growing on

321 solid medium revealed that wild-type hyphae grew parallel to the surface, while the $5 m k 3 v$

322 mutants produced a dense arrangement of highly branched, erect, aerial hyphae causing the

323 colony to rise from the surface of the medium (Figure 4). Aerial hyphae formation is promoted by

324 increased surface tension and hydrophobicity. Hydrophobicity of the central region and edge of 
325

326

327

328

329

330

331

332

333

334

335

336

337

338

339

340

341

342

343

344

345

346

347

348

349

350

351

352

353

354

355

356

the colony was determined using a technique that measures water droplet contact angle on the mycelia surface. Wild type mycelia were more hydrophobic at the edge of the colony than in the centre with water droplet contact angles of $91^{\circ}$ and $64^{\circ}$, respectively (Figure 4). The $S m k 3 v$ mutants had the opposite pattern as the center was more hydrophobic than the edge with water droplet contact angles of $33-71^{\circ}$ and $95-96^{\circ}$, respectively. The increased hydrophobicity towards the center of the mutant colonies correlated with the higher density of aerial hyphae formation in this zone.

\section{Cell wall integrity characteristics}

Previous studies demonstrated that S/t2 orthologs in other fungi played a role in cell wall biosynthesis and architecture as indicated by the decreased resistance to high temperatures and cell wall degrading enzymes in the corresponding mutants (Navarro-Garcia et al. 1995

Xu et al. 1998). To compare the cell wall integrity of wild type and Smk3v, hyphae were fragmented and incubated in lyase, a solution of cell wall degrading enzymes from T. harzianum. Hyphal fragments from the Smk3 mutants formed protoplasts at a much faster rate than fragments from wild type hyphae indicating that cell wall architecture was compromised and that lyase was able to more easily access or degrade cell wall components in the Smk3v mutant hyphae compared to wild type (Figure 5).

The sensitivity of the $S m k 3 v$ mutants was also assessed in the presence of compounds that affect the growth of yeasts and fungi with altered cell wall integrity. The growth characteristics of the $S m k 3 v .3$ mutant, a knockout generated by transposon mutagenesis, and the $S m k 3 u^{D E D}$ mutant, a point mutation that alters the ability of the MAPK to be phosphorylated, were very similar under all of the conditions tested. On solid PDA medium, the $S m k 3 v$ mutants grew slower and the rate of radial expansion was only $63-82 \%$ that of the wild-type. Increasing the osmolarity of the medium with the addition of $1.5 \mathrm{M}$ glucose or sorbitol did not affect the growth of the wild type or relative growth of the $S m k 3 v$ mutants appreciably (Figure 6). Conversely, the addition of $1 \mathrm{M}$ $\mathrm{KCl}$ or $\mathrm{NaCl}$ impacted the growth of the Smk3v mutants to a much greater extent that the wild type strain. In yeast and fungi, the chitin binding agents Calcofluor White and Congo Red inhibit cell division, but can also stimulate chitin synthesis (Roncero and Duran 1985). Addition of these compounds to the medium failed to inhibit or stimulate radial growth beyond that observed on PDA alone. Interestingly, the Smk3v mutants were highly sensitive to SDS indicating that cell 
357 membrane integrity may also be affected or that cell wall architecture is altered in such a manner

358 as to allow easier access of SDS to the plasma membrane. The Smk3v mutants were also hyper-

359 sensitive to caffeine, a compound that induces the cell wall integrity pathway and involves the

360 SLT2 (SMK3) MAPK (Fuchs and Mylonakis 2009).

361

362 Temperature effects

363 As noted above, earlier studies demonstrated that disruption of the cell wall integrity MAPK

364 pathway adversely affected the ability of mycelia to tolerate exposure to elevated temperatures,

365 but the effect on growth rate was not examined. To examine the latter, the radial expansion of

366 wild type and Smk3v mutant colonies was compared at different temperatures (Figure 7). Neither

367 the $S m k 3 v$ mutants nor the wild type was able to grow at temperatures above $37^{\circ} \mathrm{C}$. When the

368 ratio of linear colony expansion at $20^{\circ} \mathrm{C}$ and $28^{\circ} \mathrm{C}$ was compared, the mutant colonies were in fact

369 found to be more tolerant of the higher temperature. At $28^{\circ} \mathrm{C}$, the wild type colony expanded at

$37022 \%$ of its rate at $20^{\circ} \mathrm{C}$, whereas the $S m k 3 v$ mutant colonies grew at $47-51 \%$ of their rates at $20^{\circ} \mathrm{C}$.

371 This indicated that SMK3 may be involved in regulating growth rate as well as cell wall formation

372 in response to temperature stress.

373

374 Host infection

375 In other phytopathogenic fungi, loss of the cell wall integrity MAPK either rendered the mutant

376 non-pathogenic or reduced virulence. Similarly, the $S m k 3 v$ mutants exhibited reduced virulence

377 on intact $B$. napus leaves (Figure $8 \mathrm{~A}$ ). With the wild type strain, the entire area beneath the

378 mycelial inoculum became necrotic within 24 hours of inoculation, while the $5 m k 3 v$ mutants only

379 formed infection initials, i.e. small necrotic spots around the leaf veins (Figure 8A). Interestingly,

380 when mycelia from the Smk3v mutants were applied to leaves that had been stripped of cuticle

381 wax, necrosis development was equal to or even more so than of the wild type strain within 24

382 hours of inoculation (Figure 8A) indicating that SMK3 was important for infection initiation, but

383 not necessarily for lesion expansion. To further this observation, droplets of MS-Glu medium

384 containing mycelia were placed on an intact leaf surface and examined after 24 hours using a

385 dissecting microscope. Wild type hyphae radiated out of the droplet and formed infection

386 cushions that are responsible for cuticle penetration (Figure 8B) and a large necrotic area had

387 already begun to form around the infection cushions by this time. Conversely, Smk3v mutant

388 hyphae radiated outward from the droplet and grew parallel to the leaf surface. The hyphae failed 
389 to orient toward the leaf surface or aggregate to form infection cushions. No signs of necrosis 390 were observed.

391

392 
393

394

395

396

397

398

399

400

401

402

403

404

405

406

407

408

409

410

411

412

413

414

415

416

417

418

419

420

421

422

423

\section{Discussion}

\section{Identification of pathogenicity-related MAPKs in S. sclerotiorum}

MAPKs are highly conserved in fungi and yeasts and are functionally interchangeable between different organisms, even though they may have evolved to regulate slightly different biological processes (Fujioka et al. 2007; Mey et al. 2006). Two types of MAPKs, the pathogenicity and cell wall integrity MAPKs, have been demonstrated to be important for pathogenesis by filamentous phytopathogenic fungi. In S. sclerotiorum, the pathogenicity MAPK, Smk1, was found to be involved in mediating cross-talk between CAMP and pH to coordinate sclerotia formation (Chen et al. 2004). While the pathogenicity of the Smk1 mutant was not examined, disruption of orthologs in other phytopathogenic fungi severely reduced virulence and in some cases rendered them nonpathogenic (Xu et al. 1998; Hou et al. 2002). In this study, the S. sclerotiorum S/t2 ortholog, Smk3, was characterized. SLT2-like MAPKs are involved in the signaling pathway that is activated in response to extracellular factors or events that cause cell wall perturbation. Smk3 was also upregulated at the onset of the infection which further supports the notion that SMK3 may play a role in early S. sclerotiorum-host interactions. In another study, the expression of the gene encoding a cutinase which is involved in cuticle penetration was dependent on contact with a solid surface, while the expression of $S s P g 1$ was restricted to certain infection zones, such as the expanding margin of the lesion (Bashi et al. 2012). Regulation of both genes requires that the pathogen sense its environmental context and therefore the cell wall integrity MAPK pathway may be involved.

\section{Role of SMK3 in aerial hyphae formation and branching}

Disruption of Smk3 caused visually detectable alterations in colony morphology. Smk3v mutant colonies were less pigmented and more elevated than the wild type, which upon microscopic examination was found to be due to a higher density of erect, aerial hyphae. Unlike $S$. sclerotiorum, mutations in S/t2 orthologues in B. cinerea (Rui and Hahn 2007), F. graminearum (Hou et al. 2002), M. grisea (Xu et al. 1998) and Aspergillus nidulans (Bussink and Osmani 1999) reduced aerial hyphae formation, while complete loss was observed in Mycosphaerella graminicola (Mehrabi et al. 2006). Similar to the Smk3v mutant, a S. sclerotiorum adenylate cyclase mutant formed dense aerial hyphae (Jurick and Rollins 2007). 
424 The degree of aerial hyphae formation is a function of small ( 100 amino acid), surface-active, 425 secreted proteins with eight conserved cysteine residues known as hydrophobins (Wosten and 426 Willey 2000; Wessels 1997). Once secreted, hydrophobins self assemble at the hydrophilic427 hydrophobic interface into a $10 \mathrm{~nm}$ thick amphipathic protein film. This film increases water 428 tension allowing formation of aerial hyphae. The increase in aerial hyphae in Smkv mutants could 429 be due to SMK3 interaction with transcription factors that regulate hydrophobin gene expression. 430 Smkv mutant colonies were also found to be more hydrophobic at the center of the colony than 431 at the edge, while the wild type strain was more hydrophobic at the edge than the center. Fungal 432 hyphae exhibit apical dominance which allows the colony to differentiate between the edge and 433 the center of the colony. Lack of proper apical dominance may also be the reason for extensive 434 branching in the Smkv mutant hyphae. The shift in the hydrophobic zone towards the edge of the 435 colony in the Smkv mutants may be a secondary effect of the lack of apical dominance and 436 extensive branching. Hyper-branching in the Smkv mutants was consistent with an earlier finding 437 in C. purpurea which exhibited a similar phenotype upon mutation of its S/t2 ortholog.

$S m k 3 v$ mutant colonies expanded on solid medium at a slower rate than wild type colonies. Disruption of Slt2 orthologs in F. graminearum (Hou et al. 2002), C. albicans (Navarro-Garcia, 1995) and B. cinerea (Rui and Hahn 2007) caused reduced expansion on solid medium similar to the S. sclerotiorum mutant. In Mycosphaerella graminicola, no alterations in growth phenotype were observed until the fifth day on which cells showed polar growth with swollen cells forming by the eleventh day (Mehrabi et al. 2006). Unlike other fungi, the mutation had no effect on colony expansion rate in M. grisea (Xu et al. 1998) or C. lagenarium (Kojima et al. 2002). Reduced colony expansion rate has been suggested to be due to lack of osmotic tolerance. Addition of an osmotic stabilizer to cultures of a B. cinerea S/t2 orthologue disruption mutant recovered $80 \%$ of the mycelial growth and $100 \%$ of the germling elongation rate (Rui and Hahn 2007). However, in this study the addition of glucose or sorbitol to the medium failed to accelerate radial expansion of $S m k 3 v$ mutant colonies. It is also possible that the reduced colony expansion rate in the $S m k 3 v$

\section{Role of SMK3 in sclerotia formation}

454 The Smk3v mutants were unable to form sclerotia or sclerotia initials. Proper branching of hyphae 455 is known to be a prerequisite for sclerotia formation in the close relative Sclerotinia rolfsii. Hyphae 
456 of S. rolfsii were classified as either leading hyphae with ca. 40 nuclei or lateral hyphae with ca. 10

457 nuclei. Lateral hyphae with shorter intrudes $(240 \mu \mathrm{m})$ were proposed to be responsible for

458 sclerotia formation (Goujon et al. 1970). Apical dominance is regulated through a hormone-like

459 substance and prevents lateral branching and therefore sclerotia formation (Burnett 1968). In S.

460 sclerotiorum, apical dominance at the expanding colony margin may repress sclerotia formation in

461 the center of the colony. Sclerotia form at the perimeter of the colony when mycelia reach the

462 edge of the plate and only later in the interior of the colony. In all cases, sclerotia formation is

463 strongly related to proper apical dominance and branching which is altered in the Smk3v mutant.

464 Disruption of the S. sclerotiorum Smk1 MAPK gene was also found to impair sclerotia formation

465 (Chen et al. 2004) indicating that both MAPK pathways are required for normal sclerotia

466 formation.

467

468 Role of SMK3 in the response to elevated temperatures

469 Mutations in Slt2 orthologues have been demonstrated to cause sensitivity to high temperatures.

470 Cells of F. graminearum (Hou et al. 2002), Schizosaccharomyces pombe (Toda et al. 1996) and C.

471 albicans (Navarro-Garcia et al. 1996) Slt2 ortholog mutants burst upon exposure to high

472 temperatures. Interestingly, the colony expansion rate was higher in the Smk3v mutants than the

473 wild type strain when incubated at the more restrictive temperature of $28^{\circ} \mathrm{C}$ compared to $20^{\circ} \mathrm{C}$.

474 To our knowledge the role of MAPKs in the response to heat stress in filamentous fungi has not

475 been studied. In tomato, MAPK phosphorylation led to activation of a heat stress transcription

476 factor indicating that the MAPKs play a role in transducing the heat stress signal (Link et al. 2002).

477 SMK3 may be responsible for reducing growth rate at high temperatures to avoid lethal events,

478 such as cell burst, which would explain why the wild type strain grew slower than the mutant. It is

479 also possible that cell wall structure or components have been altered in an advantageous way

480 that accommodates the growth of the $S m k 3 v$ mutants at higher temperatures. It should be noted

481 that the response to environmental stresses, including elevated temperatures, are coordinated

482 through cross-talk between multiple signaling pathways including the TOR, calcineurin, MAPK and

483 CAMP-protein kinase A pathways (Fuchs and Mylonakis 2009).

Role of SMK3 in proper cell wall formation

486 The Smk3v mutant colonies were found to be more susceptible to cell wall degrading enzymes

487 than the wild type. Similar results were found in SIt2-ortholog mutants in M. grisea (Navarro- 
488

489

490

491

492

493

494

495

496

497

498

499

500

501

502

503

504

505

506

507

508

509

510

511

512

513

514

515

516

517

518

519

Garcia et al. 1998), F. graminearum (Hou et al. 2002) and M. graminicola (Mehrabi et al. 2006). An Slt2 ortholog and a second gene were found to play a redundant role in regulating cell wall integrity in C. lagenarium as mutation of the S/t2 ortholog alone did not increase the susceptibility of the cell wall to these enzymes (Kojima et al. 2002). Smk3v mutant cell walls may be less compact or rigid due to the lack of certain components or to structural changes. This flexibility could have allowed the $S m k 3 v$ mutant to grow better at high temperatures, while the associated structural changes make it more susceptible to cell wall degrading enzymes than the wild type. In this regard, the increased sensitivity of the Smk3v mutants to SDS could be attributed to alterations in cell wall architecture that permit access of the detergent to the plasma membrane. Smk3v mutants were also hyper-sensitive to caffeine, a compound that induces the cell wall integrity pathway and involves the SLT2 (SMK3) MAPK (Fuchs and Mylonakis 2009).

\section{Role of SMK3 in pathogenicity}

The $S m k 3 v$ mutants were found to be much less or even avirulent on intact leaves. Mutations in the S/t2 ortholog in B. cinerea, $B m p 3$, also resulted in reduced virulence on intact leaves and spore germlings seemed unable to sense the leaf surface, elongated excessively and were unable to form appressoria (Rui and Hahn 2007). In C. lagenarium, S/t2 ortholog mutant spores also lost their ability to form appressoria, but retained a low level of virulence due to the release of cell wall degrading enzymes and mycotoxins (Kojima et al. 2002). Magnaporthe grisea MPS1 (Xu et al. 1998 ) is also required for germ tube elongation leading to appresoria formation on solid surfaces and on the host plant. While a M. graminicola S/t2 ortholog mutant was able to initiate infection through the stomata, it was unable to expand in the plant tissue (Mehrabi et al. 2006). In our study, Smk3v mutants were at least as virulent as the wild type strain on leaves that had been stripped of cuticle wax and lesion expansion occurred rapidly once this barrier was removed or breached.

\section{Conclusion}

A wide range of pathogenicity factors may be affected by mutation of S/t2 orthologs in filamentous fungi. Only cuticle penetration appears to be impaired in Smk3v mutants since mycelia were able to expand in the leaf tissue. This could be due to lack of infection cushion formation in the mutant which, interestingly, also occurred in the adenylate cyclase mutant (Jurick and Rollins 2007). Failure to form infection cushions may be due to inability to sense the 
520 leaf surface and respond accordingly or to loss of a physiological function that is necessary for

521 infection cushion development, such as proper branching. The corresponding protein in Candida

522 albicans, Mkc1p, is involved in the regulation of surface contact-dependent processes leading to

523 filamentous invasive growth (Kumamoto 2005). Considering the overlap in functions between

524 CAMP and SMK3 signaling, including aerial hyphae formation, branching and sclerotia formation,

525 it is possible that both signaling mechanisms regulate infection cushion formation as well. In $S$.

526 sclerotiorum, the production of hydrolytic enzymes (cutinases) required for cuticular wax

527 degradation is induced by contact with solid surfaces (Bashi et al. 2012) and infectivity and

528 trichothecene production are linked to an SLT2-like MAPK in Fusarium species (Hou et al. 2002;

529 Zhang et al. 2011). This suggests that in S. sclerotiorum the detection of surface integrity leading

530 to infection cushion formation and subsequent deployment of virulence determinants, such as

531 hydrolytic enzymes and toxins, which are required for infection initiation, may be co-dependent

532 on the SMK3 MAPK pathway. Interestingly, the FUS3-like MAPK is also associated with surface

533 sensing and host penetration in fungal phytopathogens (Leroch et al. 2015; Perez-Nadales and Di

534 Pietro 2015), suggesting that the two MAPK pathways may share common partners. In

535 conclusion, the functions regulated by fungal MAPKs are diverse and vary even in closely related

536 species; therefore, it is important to characterize the ortholog associated with each species of

537 interest. The availability of a near complete S. sclerotiorum genome sequence (Amselem et al.

538 2011) and the ability to generate disruption mutations through homologous recombination or

539 gene silencing should allow discovery and characterization of additional signaling components

540 required for interaction with host plants.

541

542

543 Acknowledgements

544 Funding for this work was provided by Sask Canola, the Province of Saskatchewan through the

545 Agriculture Development Fund and the Government of Canada through the Agriculture Innovation 546 Program. 
547

548

549

550

551

552

553

554

555

556

557

558

559

560

561

562

563

564

565

566

567

568

569

570

571

572

573

574

575

576

577

References

Abawi, G. S., and Grogan, R. G. 1975. Source of primary inoculum and effects of temperature and moisture on infection of beans by Whetzelinia sclerotiorum. Phytopathology, 65: 300-309.

Amselem, J., Cuomo, C.A., van Kan, J.A., Viaud, M., Benito, E.P., Couloux, A., Coutinho, P.M., de Vries, R.P., Dyer, P.S., Fillinger, S., Fournier, E., Gout, L., Hahn, M., Kohn, L., Lapalu, N., Plummer, K.M., Pradier, J.M., Quévillon, E., Sharon, A., Simon, A., ten Have, A., Tudzynski, B., Tudzynski, P., Wincker, P., Andrew, M., Anthouard, V., Beever, R.E., Beffa, R., Benoit, I., Bouzid, O., Brault, B., Chen, Z., Choquer, M., Collémare, J., Cotton, P., Danchin, E.G., Da Silva, C., Gautier, A., Giraud, C., Giraud, T., Gonzalez, C., Grossetete, S., Güldener, U., Henrissat, B., Howlett, B.J., Kodira, C., Kretschmer, M., Lappartient, A., Leroch, M., Levis, C., Mauceli, E., Neuvéglise, C., Oeser, B., Pearson, M., Poulain, J., Poussereau, N., Quesneville, H., Rascle, C., Schumacher, J., Ségurens, B., Sexton, A., Silva, E., Sirven, C., Soanes, D.M., Talbot, N.J., Templeton, M., Yandava, C., Yarden, O., Zeng, Q., Rollins, J.A., Lebrun, M.H. and Dickman, M. (2011) Genomic analysis of the necrotrophic fungal pathogens Sclerotinia sclerotiorum and Botrytis cinerea. PLoS Genet. 7, e1002230. doi: 10.1371/journal.pgen.1002230.

Bashi, Z., Hegedus, D., Buchwaldt, L., Rimmer, R., and Borhan, M. 2010a. Expression and regulation of Sclerotinia sclerotiorum necrosis and ethylene-inducing peptides (NEPs). Mol. Plant Pathol., 11: 43-53.

Bashi, Z., Khachatourians, G.G., and Hegedus, D.D. 2010b. Isolation of fungal homokaryotic lines from heterokaryotic transformants by sonic disruption of mycelia. Biotechniques, 48: 351354.

Bashi, Z.D., Rimmer, S.R., Khachatourians, G.G., and Hegedus, D.D . 2012. Factors governing the regulation of Sclerotinia sclerotiorum cutinase $A$ and polygalacturonase 1 during different stages of the infection. Can. J. Microbiol., 58: 605-616.

Bashi, Z.D., Rimmer, S.R., Khachatourians, G.G. and Hegedus, D.D. 2013. Brassica napus polygalacturonase inhibitor proteins inhibit Sclerotinia sclerotiorum polygalacturonase enzymatic and necrotizing activities and delay symptoms in transgenic plants. Can. J. Microbiol. 59: 79-86.

Boland, G.J., and Hall, R. 1994. Index of plant hosts of Sclerotinia sclerotiorum. Can. J. Plant Pathol., 16: 93-108.

Burnett, H. 1968. Fundamentals in Mycology. Arnold: London, UK. 
578 Bussink, H. and Osmani, S. 1999. A mitogen-activated protein kinase (MPKA) is involved in 579 polarized growth in the filamentous fungus Aspergillus nidulans. FEMS Microbiol. Lett., 173: $580 \quad 117-125$.

581 Chau, H., Si, B., Goh, Y., and Vujanovic, V. 2009. A novel method for identifying hydrophobicity on 582 fungal surfaces. Mycol .Res., 113: 1046-1052.

583 Chen, C., Harel, A., Gorovoits, R., Yarden, O., and Dickman, M.B. 2004. MAPK regulation of 584 sclerotial development in Sclerotinia sclerotiorum is linked with $\mathrm{pH}$ and cAMP sensing. Mol. $585 \quad$ Plant-Microbe Interact., 17: 404-413.

586 Chen, C. and Dickman, M.B. 2005. cAMP blocks MAPK activation and sclerotial development via 587 Rap-1 in a PKA-independent manner in Sclerotinia sclerotiorum. Mol. Microbiol., 55: 299-311. 588 Cotton, P., Kasza, Z., Bruel, C., Rascle, C. and Fevre, M. 2003. Ambient pH controls the expression 589 of endopolygalacturonase genes in the necrotrophic fungus Sclerotinia sclerotiorum. FEMS $590 \quad$ Microbiol. Lett., 227: 163-169.

591 De Nobel, H. 2000. Cell wall maintenance in fungi. Trends Microbiol., 8: 344-345.

592 Di Pietro, A., Garcia-MacEira, I., Meglecz, E., and Roncero, I. 2001. A MAP kinase of the vascular 593 wilt fungus Fusarium oxysporum is essential for root penetration and pathogenesis. Mol. 594 Microbiol., 39: 1140-1152.

595 Duan, Y., Ge, C., Liu, S., Wang, J. and Zhou, M. 2013. A two-component histidine kinase Shk1 596 controls stress response, sclerotial formation and fungicide resistance in Sclerotinia 597 sclerotiorum. Mol. Plant Pathol., 14: 708-18.

598 Erental, A., Harel, A. and Yarden, O. 2007. Type 2A phosphoprotein phosphatase is required for 599 asexual development and pathogenesis of Sclerotinia sclerotiorum. Mol. Plant-Microbe $600 \quad$ Interact., 20: 944-54.

601 Erental, A., Dickman, M.B. and Yarden, O. 2008. Sclerotial development in Sclerotinia 602 sclerotiorum: awakening molecular analysis of a "Dormant" structure. Fungal Biol. Rev., 22: 6$603 \quad 16$.

604 Favaron, F., Sella, L. and D'Ovidio, R. 2004. Relationships among endo-polygalacturonase, oxalate, $605 \mathrm{pH}$, and plant polygalacturonase-inhibiting protein (PGIP) in the interaction between 606 Sclerotinia sclerotiorum and soybean. Mol. Plant-Microbe Interact., 17: 1402-1409.

607 Fuchs, B.B., and Mylonakis, E. 2009. Our paths might cross: the role of the fungal cell wall integrity 608 pathway in stress response and cross talk with other stress response pathways. Euk. Cell, 8: $609 \quad 1616-1625$. 
610

611

612

613

614

615

616

617

618

619

620

621

622

623

624

625

626

627

628

629

630

631

632

633

634

635

636

637

638

639

Fujioka, T., Mizutani, O., Furukawa, K., Sato, N., Yoshimi, A.,Yamagata, Y., Nakajima, T., and Abe, K. 2007. MpkA-dependent and -independent cell wall integrity signaling in Aspergillus nidulans. Eukaryot. Cell, 6: 1479-1510.

Girard, V., Fevre, M. and Bruel, C. 2004. Involvement of cyclic AMP in the production of the acid protease Acp1 by Sclerotinia sclerotiorum. FEMS Microbiol. Lett., 237: 227-233.

Godoy, G., Steadman, J.R., Dickman, M.B. and Dam, R. 1990. Use of mutants to demonstrate the role of oxalic acid in pathogenicity of Sclerotinia sclerotiorum on Phaseolus vulgaris. Physiol. Mol. Plant Pathol. 37: 179-191.

Goujon, M. 1970. Mecanismes physiologiques de la formation des sclerotes chez le Corticium rofsii (Sacc.) curzi. Physiol. Veg., 8: 349-360.

Gustin, M., Albertyn, J., Alexander, M., and Davenport, K. 1998. MAP kinase pathways in the yeast Saccharomyces cerevisiae. Microbiol. Mol. Biol. Rev., 62: 1264-1300.

Guyon, K., Balague, C., Roby, D., abd Raffaele, S. 2014. Secretome analysis reveals effector candidates associated with broad host range necrotrophy in the fungal plant pathogen Sclerotinia sclerotiorum. BMC Genomics, 15: 336, doe: 10.1186/1471-2164-15-336.

Hanks, S.K. 2003. Genome analysis of the eukaryotic protein kinase superfamily: a perspective. Genome Biol., 4: 111.

Harel, A., Rorovitis, R. and Yarden, O. 2005. Changes in protein kinase A activity accompany sclerotial development in Sclerotinia sclerotiorum. Phytopathology, 95: 397-404.

Harel, A., Bercovich, S. and Yarden, O. 2006. Calcineurin is required for sclerotial development and pathogenicity of Sclerotinia sclerotiorum in an oxalic acid-independent manner. Mol. PlantMicrobe Interact., 19: 682-93.

Hegedus, D.D., Gerbrandt, K., and Coutu, C . 2015. The protein kinase superfamily of the necrotrophic fungal plant pathogen, Sclerotinia sclerotiorum. Mol. Plant Pathol., (in press DOI: $10.1111 / \mathrm{mpp} .12321)$.

Horton, R.M., Cai, Z.L., Ho, S.N., and Pease, L.R. 1990. Gene splicing by overlap extension: Tailormade genes using the polymerase chain reaction. BioTechniques, 8: 528-535

Hou, Z., Xue, C., Peng, Y., Katan, T., Kistler, H,C., and Jin-Rong, X. 2002. A Mitogen-activated protein kinase gene (MGV1) in Fusarium graminearum is required for female fertility, heterokaryon formation, and plant infection. Mol. Plant-Microbe Interact., 15: 1119-1127. 
640 Jurick, W., and Rollins, J. 2007. Deletion of the adenylate cyclase (sac1) gene affects multiple 641 developmental pathways and pathogenicity in Sclerotinia sclerotiorum. Fung. Genet. Biol., 44: $642 \quad 521-530$.

643 Jurick, W.M., Dickman, M.B. and Rollins, J.A. 2004. Characterization and functional analysis of a 644 cAMP-dependent protein kinase A catalytic subunit gene (pka1) in Sclerotinia sclerotiorum. 645 Physiol. Mol. Plant Pathol., 64: 155-163.

646 Kabbage, M., Yarden, O. and Dickman, M.B. 2015. Pathogenic attributes of Sclerotinia 647 sclerotiorum: Switching from a biotrophic to necrotrophic lifestyle. Plant Sci. 233: 53-60.

648 Kasza, Z., Vagvolgyi, C., Fevre, M. and Cotton, P., 2004. Molecular characterization and in planta 649 detection of Sclerotinia sclerotiorum endopolygalacturonase genes. Curr. Microbiol. 48: 20865013.

651 Kim, H.J., Chen, C., Kabbage, M. and Dickman, M.B. 2011. Identification and characterization of 652

Leroch, M., Mueller, N., Hinsenkamp, I. and Hahn, M. 2015. The signaling mucin Msb2 regulates

659 surface sensing and host penetration via BMP1-MAP kinase signaling in Botrytis cinerea. Mol. Plant Pathol. (epub ahead of print). DOI:10.1111/mpp.12234.

Lev, S., Sharon, A., Hadar, R., Ma, H., and Horwitz, B. 1999 A mitogen-activated protein kinase of 663 the corn leaf pathogen Cochliobolus heterostrophus is involved in conidiation, appressorium formation, and pathogenicity: Diverse roles for mitogen-activated protein kinase homologs in Interaction of Sclerotinia sclerotiorum with Brassica napus: Cloning and characterization of 
672

673

674

675

676

677

678

679

680

681

682

683

684

685

686

687

688

689

690

691

692

693

694

695

696

697

698

699

700

701

702

endo- and exo-polygalacturonases expressed during saprophytic and parasitic modes. Fungal Genet. Biol. 41: 754-765.

Liang Y., Yajima W., Davis M.R., Kav, N.V. and Strelkov, S.E. 2013. Disruption of a gene encoding a hypothetical secreted protein from Sclerotinia sclerotiorum reduces its virulence on canola (Brassica napus). Can. J. Plant Pathol., 35: 46-55.

Link, V., Sinha, A., Vashista, P., Hofmann, M., Proels, R., Ehness, R., and Roitsch, T. 2002. A heatactivated MAP kinase in tomato: a possible regulator of the heat stress response. FEBS Lett., 531: 179-183.

Lumsden, R. D. 1979 Histology and physiology of pathogenesis in plant disease caused by Sclerotinia species. Phytopathology., 69: 890-896.

Lumsden, R. D., and Dow, R. L. 1973. Histopathology of Sclerotinia sclerotiorum infection of bean. Phytopathology, 63: 708-715.

Lyu, X., Shen, C., Fu, Y., Xie, J., Jiang, D., Li, G., and Cheng, J. 2015. Comparative genomic and transcriptional analyses of the carbohydrate-active enzymes and secretomes of phytopathogenic fungi reveal their significant roles during infection and development. Sci. Rep., 5: 15565, DOI: 10.1038/srep15565.

Lyu, X., Shen, C., Fu, Y., Xie, J., Jiang, D., Li, G., and Cheng, J. 2016. A small secreted virulencerelated protein Is essential for the necrotrophic interactions of Sclerotinia sclerotiorum with its host plants. PLoS Pathogens, 12(2): e1005435. doi:10.1371/journal. ppat.1005435

Martel, M.B., Letoublon, R. and Fevre, M. 1996. Purification of endopolygalacturonases from Sclerotinia sclerotiorum: multiplicity of the complex enzyme system. Curr. Microbiol. 33: 243248.

Mayorga, M., and Gold, S. 1999. A MAP kinase encoded by the ubc3 gene of Ustilago maydis is required for filamentous growth and full virulence. Mol. Microbiol., 34: 485-497.

Mehrabi, R., Van der Lee, T., Waalwijk, C., and Kema, G. 2006. MgSlt2, a cellular integrity MAP kinase gene of the fungal wheat pathogen Mycosphaerella graminicola, is dispensable for penetration but essential for invasive growth. Mol. Plant-Microbe Interact., 19: 389-398.

Mey, G., Held, K., Scheffer, J., Tenberge, K., and Tudzynski, P. 2006 CPMK2, an SLT2-homologous mitogen-activated protein (MAP) kinase, is essential for pathogenesis of Claviceps purpurea on rye: Evidence for a second conserved pathogenesis-related MAP kinase cascade in phytopathogenic fungi. Mol. Microbiol., 46: 305-318. 
703

704

705

706

707

708

709

710

711

712

713

714

715

716

717

718

719

720

721

722

723

724

725

726

727

728

729

730

731

732

733

Perez-Nadales, E. and Di Pietro, A. 2015. The transmembrane protein Sho1 cooperates with the mucin Msb2 to regulate invasive growth and plant infection in Fusarium oxysporum. Mol. Plant Protect. 16: 593-603.

Navarro-Garcia, F., Sanchez, M., Pla, J., and Nombela, C. 1995. Functional characterization of the MKC1 gene of Candida albicans, which encodes a mitogen-activated protein kinase homolog related to cell integrity. Mol. Cell. Biol., 15: 2197-2206.

Pan, Y., Xu, Y., Li, X., Yao, C., and Gao, Z. 2015. SsPemG1 encodes an elicitor-homologous protein and regulates pathogenicity in Sclerotinia sclerotiorum. Physiol. Mol. Plant Pathol. 92: 70-78.

Papapostolou, I., Sideri, M. and Georgiou, C.D. 2014. Cell proliferating and differentiating role of $\mathrm{H} 2 \mathrm{O} 2$ in Sclerotium rolfsii and Sclerotinia sclerotiorum. Microbiol. Res., 169 : 527-32.

Poussereau, N., Creton, S., Billon-Grand, G., Rascle, C. and Fevre, M. 2001a. Regulation of acp1, encoding a non-aspartyl acid protease expressed during pathogenesis of Sclerotinia sclerotiorum. Microbiology, 147: 717-726.

Poussereau, N., Gente, S., Rascle, C., Billon-Grand, G. and Fevre, M. 2001b. aspS encoding an unusual aspartyl protease from Sclerotinia sclerotiorum is expressed during phytopathogenesis. FEMS Microbiol. Lett. 194: 27-32.

Rollins, J.A. 2003. The Sclerotinia sclerotiorum pac1 gene is required for sclerotial development and virulence. Mol. Plant-Microbe Interact., 16: 785-795.

Rollins, J.A. and Dickman, M.B. 1998. Increase in endogenous and exogenous cyclic AMP levels inhibits sclerotial development in Sclerotinia sclerotiorum. Appl. Environ. Microbiol., 64: 2539-2544.

Rollins, J.A. and Dickman, M.B. 2001. pH signaling in Sclerotinia sclerotiorum: identification of a pacC/RIM1 homolog. Appl. Environ. Microbiol., 67: 75-81.

Roncero. C., and Duran, A. 1985. Effect of Calcofluor White and Congo Red on fungal cell wall morphorgenesis: In vivo activation of chitin polymerization. J. Bacteriol., 163: 1180-1185.

Rui, O., and Hahn, M. 2007. The SIt2-type MAP kinase Bmp3 of Botrytis cinerea is required for normal saprotrophic growth, conidiation, plant surface sensing and host tissue colonization. Mol. Plant Pathol ., 8: 173-184.

Takano, Y., Kikuchi, T., Kubo, Y., Hamer, E., Mise, K., and Furusawa, I. 2000. The Colletotrichum lagenarium MAP kinase gene CMK1 regulates diverse aspects of fungal pathogenesis. Mol. Plant-Microbe Interact., 13: 374-383. 
734 Toda, T., Dhut, S., Superti-Furga, G., Gotoh, Y., Nishida, E., Sugiura, R., and Kuno, T. 1996. The 735 fission yeast pmk1+ gene encodes a novel mitogen-activated protein kinase homolog which

736 regulates cell integrity and functions coordinately with the protein kinase C pathway. Mol.

737 Cell. Biol., 16: 6752-6764.

738 Vacher, S., Cotton, R. and Fevre, M. 2003. Characterization of a SNF1 homologue from the 739 phytopathogenic fungus Sclerotinia sclerotiorum. Gene, 310: 113-121.

740 Vautard-Mey, G., Cotton, P. and Fevre, M. 1999. Expression and compartmentation of the glucose

741 repressor CRE1 from the phytopathogenic fungus Sclerotinia sclerotiorum. Eur. J. Biochem.

$742 \quad$ 266: 252-259.

743 Vautard-Mey, G. and Fevre, M. 2000. Mutation of a putative AMPK phosphorylation site abolishes

744 the repressor activity but not the nuclear targeting of the fungal glucose regulator CRE1. Curr.

$745 \quad$ Genet., 37: 328-332.

746 Wessels, J. 1997. Hydrophobins, proteins that change the nature of the fungal surface. Adv.

747 Microbial. Physiol., 38: 1-45.

748 Wosten, H., and Willey, J. 2000. Surface-active proteins enable microbial aerial hyphae to grow 749 into the air. Microbiology, 146: 767-773.

750 Xiao, X., Xie, J., Cheng, J., Li, G., Yi, X., Jiang, D., and Fu, Y. 2014. Novel secretory protein Ss-Caf1 of

751 the plant-pathogenic fungus Sclerotinia sclerotiorum is required for host penetration and

752 normal sclerotial development. Mol. Plant-Microbe Interact., 27: 40-55.

753 Xu, J., Staiger, C., and Hamer, J. 1998. Inactivation of the mitogen-activated protein kinase Mps1

754 from the rice blast fungus prevents penetration of host cells but allows activation of plant

755 defense responses. Proc. Natl. Acad. Sci. USA, 95: 12713-12718. 
$756 \mathrm{Xu}, \mathrm{J}-\mathrm{R} .2000$. MAP kinases in fungal pathogens. Fungal Genet. Biol., 31: 137-152.

757 Zhang, Y., Choi, Y-E., Zou, X., and Xu, J-R. 2011. The FvMK1 mitogen-activated kinase gene

758 regulates condiation, pathogenesis, and fumonisin production in Fusarium verticillioides.

759 Fungal Genet. Biol., 48: 71-79.

760 Zhang, H., Wu, Q., Cao, S., Zhao, T., Chen, L., Zhuang, P., Zhou, X. and Gao, Z. 2014. A novel

761 protein elicitor (SsCut) from Sclerotinia sclerotiorum induces multiple defense responses in

762 plants. Plant Mol. Biol. 86: 495-511.

763 Zheng, L., Campbell, M., Murphy, J., Lam, S., and Xu, J-R. 2000. The BMP1 gene is essential for

764 pathogenicity in the gray mold fungus Botrytis cinerea. Mol. Plant-Microbe Interact., 13: 724-

$765 \quad 732$.

766 Zhu, W., Wei, W., Fu, Y., Cheng, J., Xie, J., Li, G., Yi, X., Kang, Z., Dickman, M.B., and Jiang, D. 2013.

767 A secretory protein of necrotrophic fungus Sclerotinia sclerotiorum that suppresses host

768 resistance. PLoS One, 8(1): e53901. doi: 10.1371/journal.pone.0053901.

769 


\section{$770 \quad$ Figure Legends}

771 Figure 1. Alteration in the phosphorylation state of $S$. sclerotiorum ERK1/ERK2 type MAPKs in 772 response to contact with solid surfaces.

773 Mycelia were grown in MS-Glu liquid medium and then placed in contact with various solid

774 surfaces for $10 \mathrm{~min}$. Western blot analysis was conducted using an antibody specific to

775 phosphorylated forms of ERK1/ERK2 MAPKs. Asterisks ( $\left.{ }^{*}\right)$ indicate the location of MAPKs

776 exhibiting increased phosphorylation in mycelium placed in contact with solid surfaces (leaf,

777 Parafilm, glass, or leaf wax) relative to mycelia grown in liquid culture. The bottom panel shows

778 the same membrane treated with Ponceau stain to detect protein loaded in each lane.

779

780

781

782

783

784

785

786

787

Figure 2. Alignment of SLT2-like MAPKs from filamentous fungi and yeasts.

Alignment of S. sclerotiorum SMK3 (1G05445) with SLT2 orthologs including Aspergillus nidulans MPKA (AAD24428.1), Botrytis cinerea BMP3 (ABJ51957.1), Blumeria graminis MPK2

(AAG53655.1), Candida albicans MKC1 (AAL50116.1), Claviceps purpurea CPMK2 (CAC87145.1), Colletochricum lagenarium MAF1 (AAL50116.1), Fusarium graminearum MGV1 (AAM13670.1), Magnaporthe grisea MPS1 (AAC63682.1) and Saccharomyces cerevisiae SLT2 (CAA41954.1). Identical amino acids (white on black background) and those with conserved properties (black on gray) are shown. The ERK1/ERK2 type phosphorylation site (TEY) is indicated by asterisks (*).

788

789

790

Figure 3. Expression of Smk1 and Smk3 in response to contact with leaf surfaces.

Northern blot analysis showing gene expression in liquid minimal salts medium and after contact with intact $B$. napus leaves $(24 \mathrm{~h}$ ) or leaves stripped of cuticular wax in the presence or absence of glucose. The lower panels show the rRNA loaded in each lane.

793

794

Figure 4. The effect of $S m k 3$ mutation on S. sclerotiorum sclerotia formation, mycelial development, and mycelial hydrophobicity.

Panel A: Wild type (1980) and Smk3v mutant colonies three weeks after inoculation of potato

797 dextrose agar. Sclerotia were observed with the wild type, but not the mutant lines. Panel B: Light microscopic images of the wild type strain and $S m k 3 u$ mutants growing in minimal salt-glucose liquid medium. Mycelial branching is more frequent in the mutant mycelia than in the wild type. 
802

803

804

805

806

807

808

809

810

811

812

813

814

815

816

817

818

819

820

821

822

823

824

825

826

827

828

829 mycelia formation in the mutants. Panel C: Water droplet contact angle on S. sclerotiorum wild type and Smk3u mutant mycelia surface in the center (black bars) and the edge (grey bars) of the colony. Error bars indicate standard deviation of three replicates. Lower case letter indicate significant differences in hydrophobicity between the edge and the center of the colony for each line (Student t-test $p \leq 0.05$ ). Upper case letters indicate differences between lines at either the edge or the center of the colony (Tukey's least significant test $p \leq 0.05$ ).

Figure 5. The effect of Smk3 mutation on S. sclerotiorum cell wall integrity as determined by incubation with cell wall degrading enzymes.

Time course study showing formation of protoplasts. Upper case letters indicate differences in protoplast formation between lines at each time point (Tukey's least significant test $p \leq 0.05$ ).

Figure 6. Radial expansion of S. sclerotiorum wild type (1980) and Smk3v mutant colonies on PDA supplemented with compounds that affect yeast and fungal mutants with altered cell wall integrity. PDA, PDA + 1.5 M glucose, PDA + 1.5 M sorbitol, PDA + $1 \mathrm{M} \mathrm{KCl}, \mathrm{PDA}+1 \mathrm{M} \mathrm{NaCl}, \mathrm{PDA}+$ 300 uM Congo Red, PDA + 1.5 mM Calcofluor White, PDA + 0.01\% SDS, PDA + 10 mM caffeine. Error bars in graphs indicate standard deviation of four replicates.

Figure 7. Effect of Smk3 mutation on S. sclerotiorum growth at elevated temperature. Colony expansion of wild type (1980) and Smk3u mutants on PDA at 20 or $28^{\circ} \mathrm{C}$.

Figure 8. Effect of Smk3 mutation on S. sclerotiorum infection of B. napus leaves.

Panel A: Intact B. napus leaves or leaves stripped of cuticle wax 24 hours after inoculation with wild type S. sclerotiorum or Smk3v mutants. The upper panels show leaves with the mycelial inoculum, while in the lower panels mycelia has been removed to reveal the affected tissue beneath. Panel B: Upper panels show B. napus leaves 24 hours after inoculation with droplets containing wild type or $5 m k 3 v$ mutant mycelia. Lower panels are magnified to better depict the presence or absence of infection cushions (arrows). 


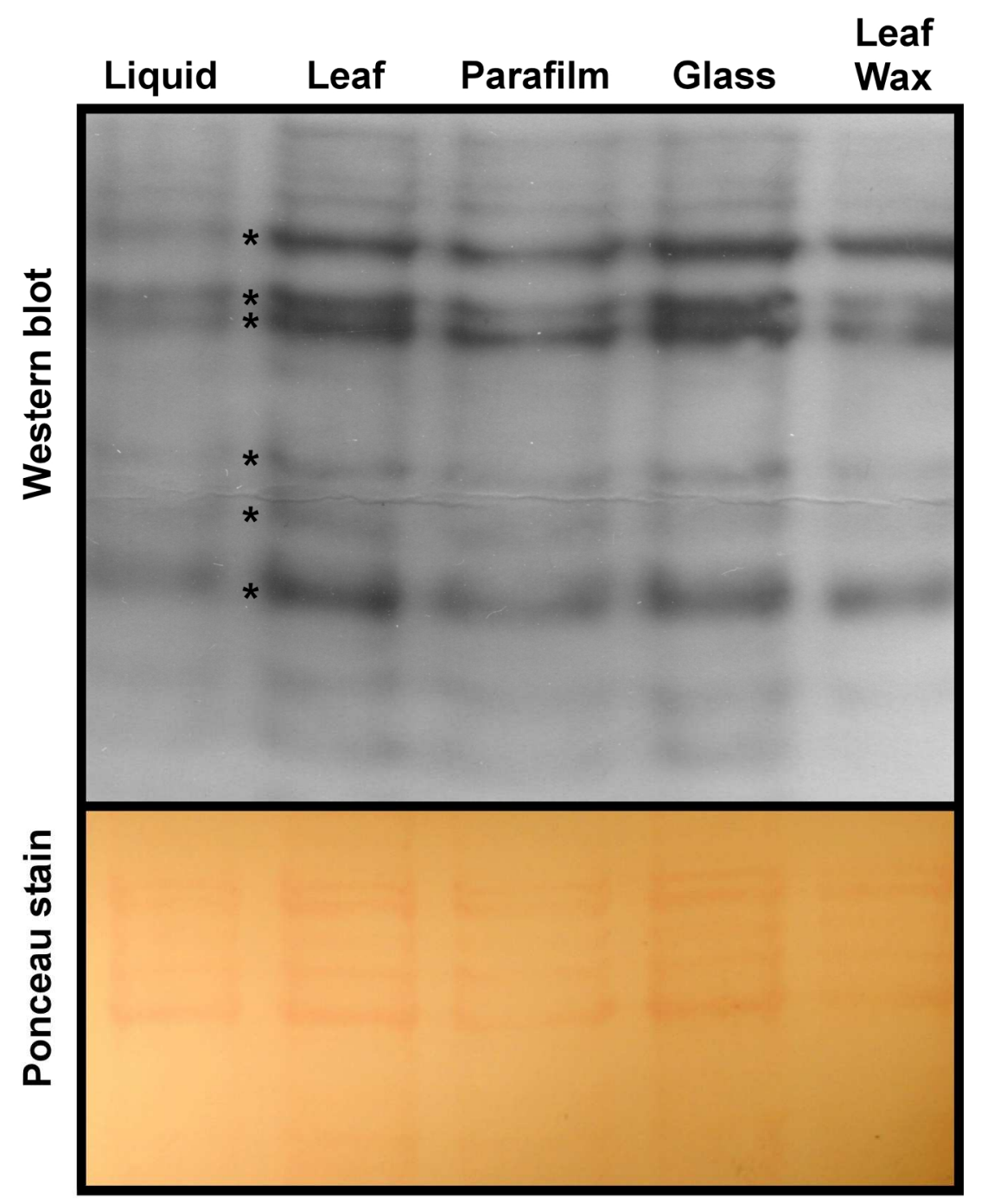

Figure 1

$157 \times 223 \mathrm{~mm}(300 \times 300$ DPI $)$ 
S. sclerotiorum SMK

A. nidulans MPKA

B. cinerea BMP3

B. graminis MPK2

C. Iagenarium MAFI

C. purpurea CPMK2

F. graminearum MGV1

M. grisea MPS1

S. cerevisiae SLT2

S. sclerotiorum SMK

A. nidulans MPKA

B. cinerea BMP3

B. graminis MPK2

C. Iagenarium MAF1

C. purpurea CPMK2

F. graminearum MGV

M. grisea MPSI

S. cerevisiae SLT2

S. sclerotiorum SMK

A. nidulans MPKA

$B$. cinerea BMP3

B. graminis MPK2

C. lagenarium MAF

F. graminearum MGV1

M. grisea MPS1

S. cerevisiae SLT2

S. sclerotiorum SMK

A. nidulans MPKA

B. cinerea BMP3

B. graminis MPK2

C. Iagenarium MAF1

C. purpurea CPMK2

F. graminearum MGV1

M. grisea MPS1

S. cerevisiae SLT2
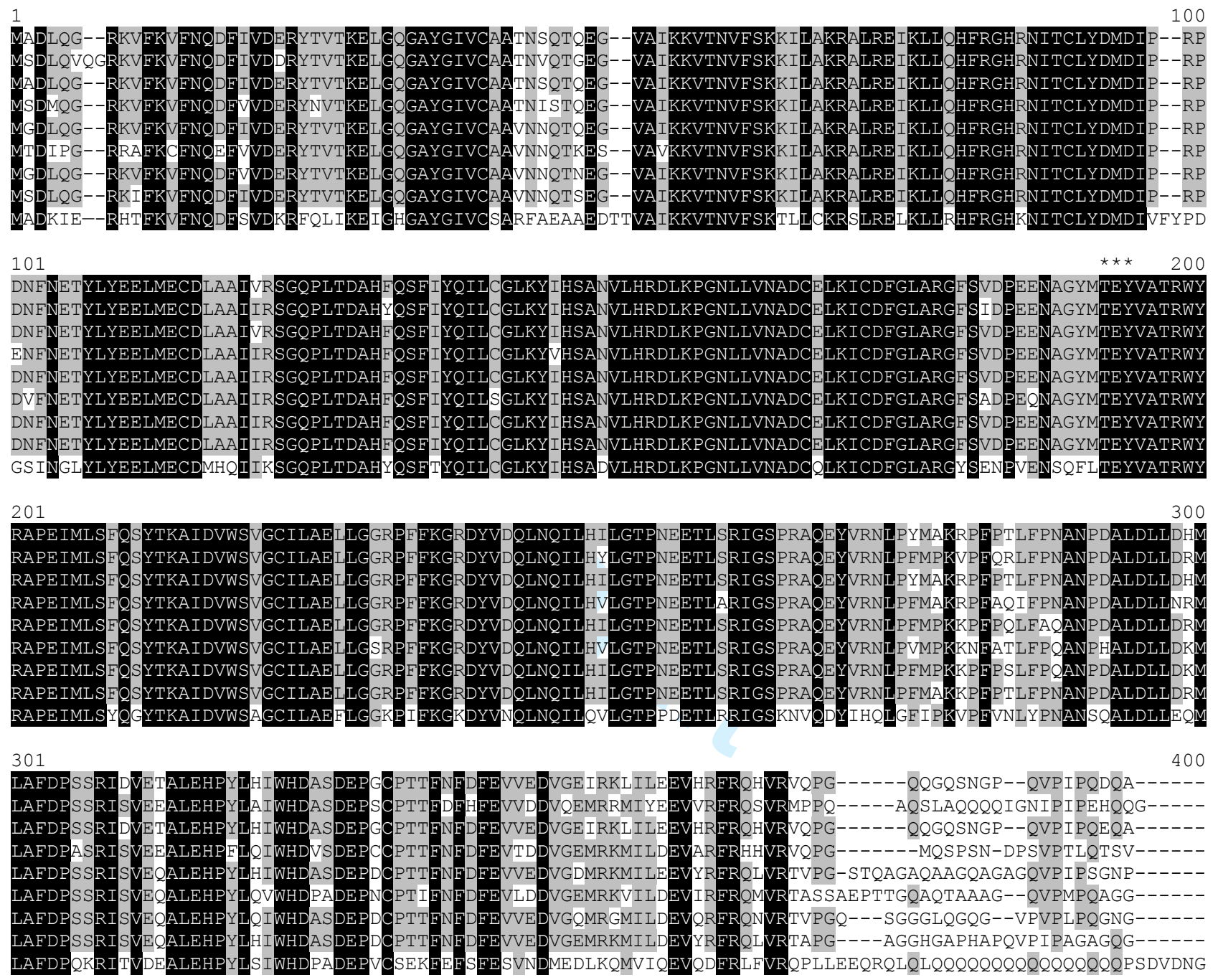

S. sclerotiorum SMK3

A. nidulans MPKA

B. Cinerea BMP3

B. graminis MPK2

C. Iagenarium $\mathrm{MAF} 1$

C. purpurea CPMK2

F. graminearum MGV1

M. grisea MPSI

S. cerevisiae SLT2

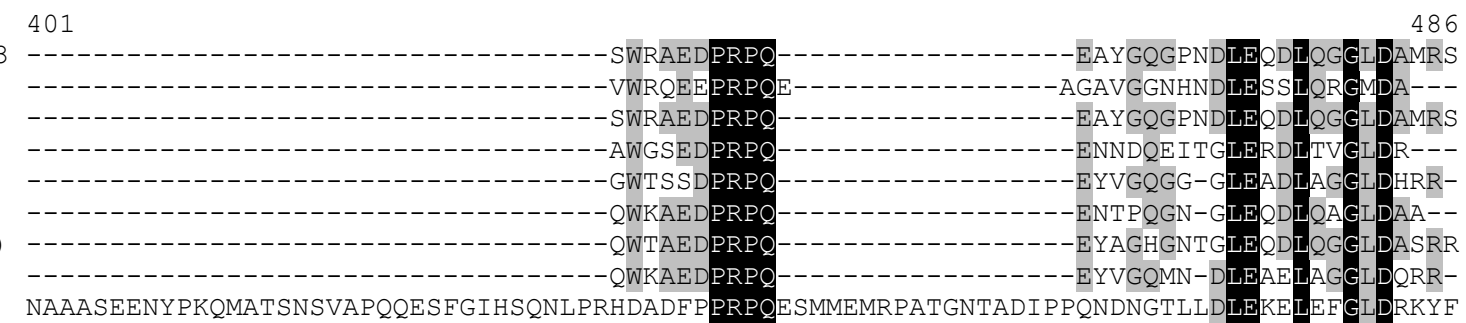




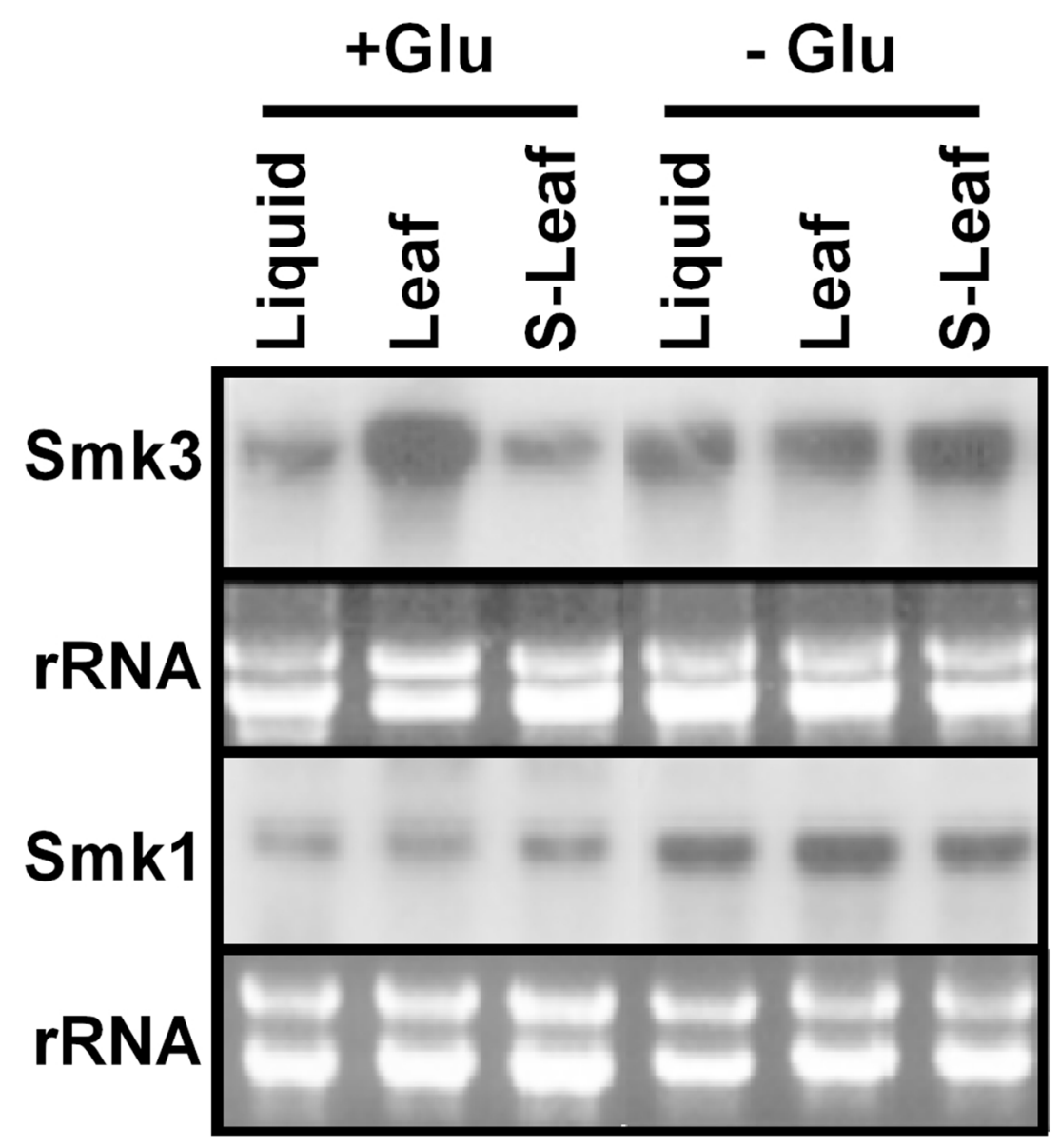

Figure 3

$96 \times 123 \mathrm{~mm}(300 \times 300 \mathrm{DPI})$ 

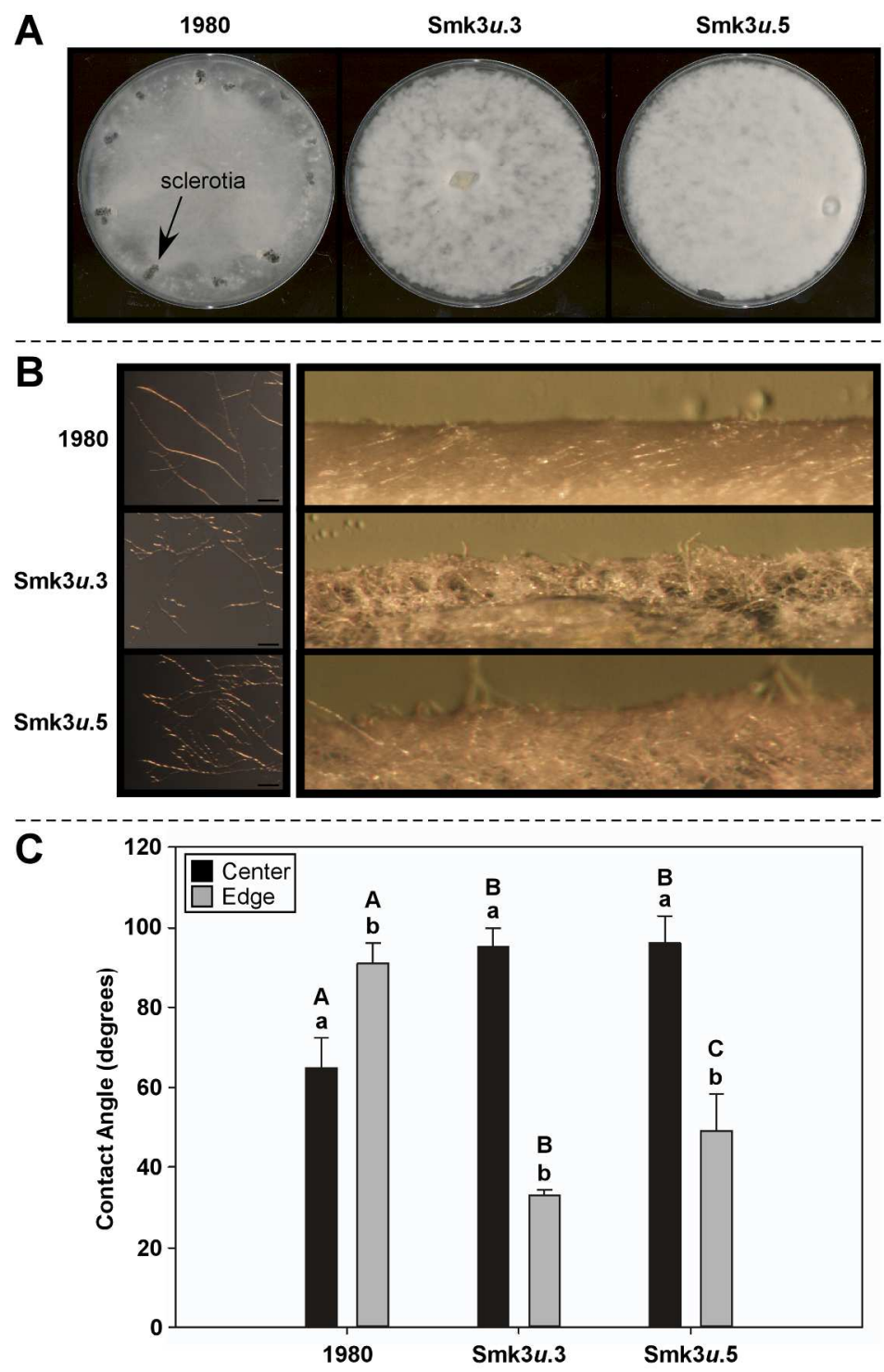

Figure 4.

$170 \times 267 \mathrm{~mm}(300 \times 300$ DPI $)$ 


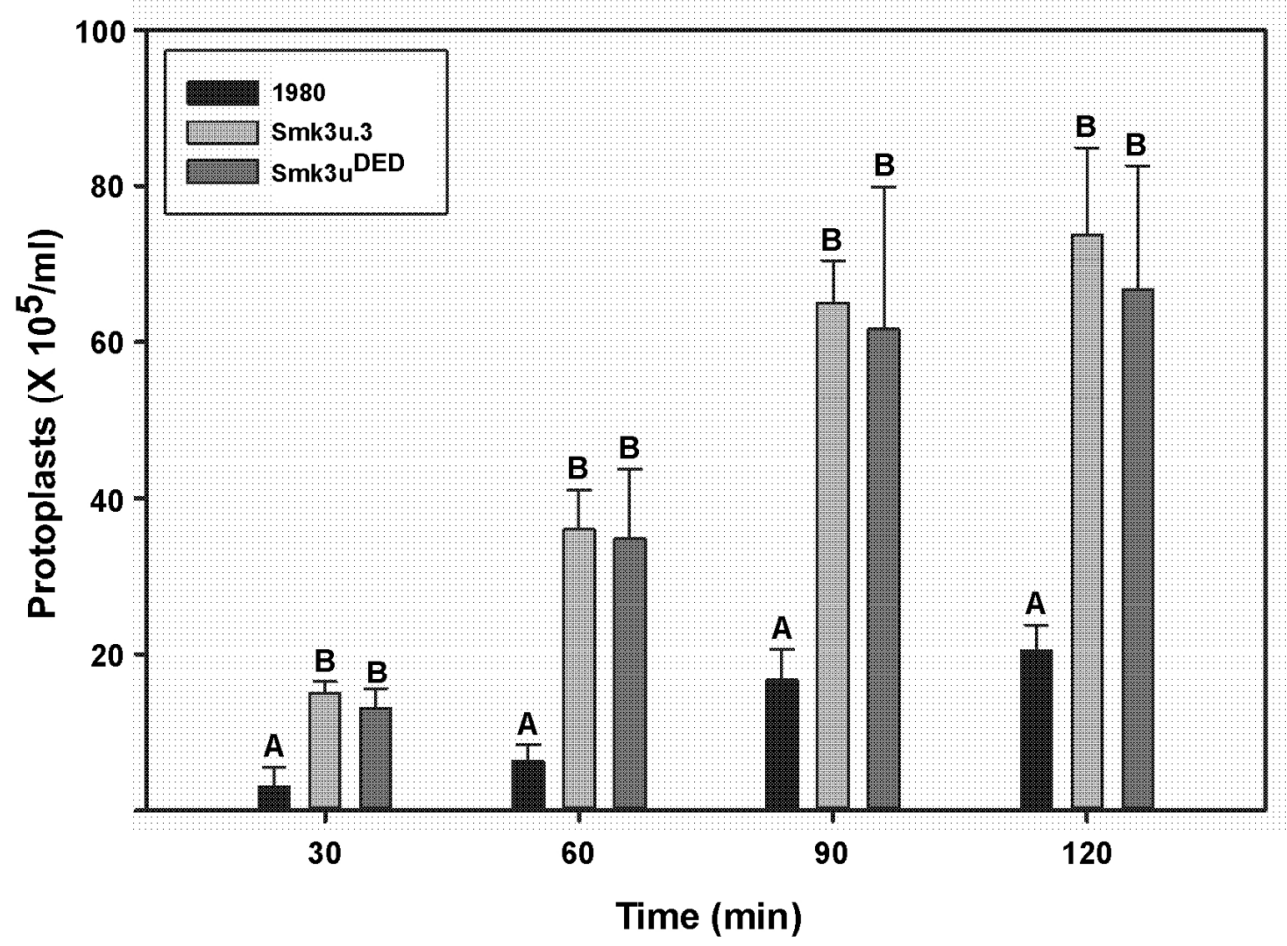

Figure 5.

$147 \times 141 \mathrm{~mm}(300 \times 300 \mathrm{DPI})$ 


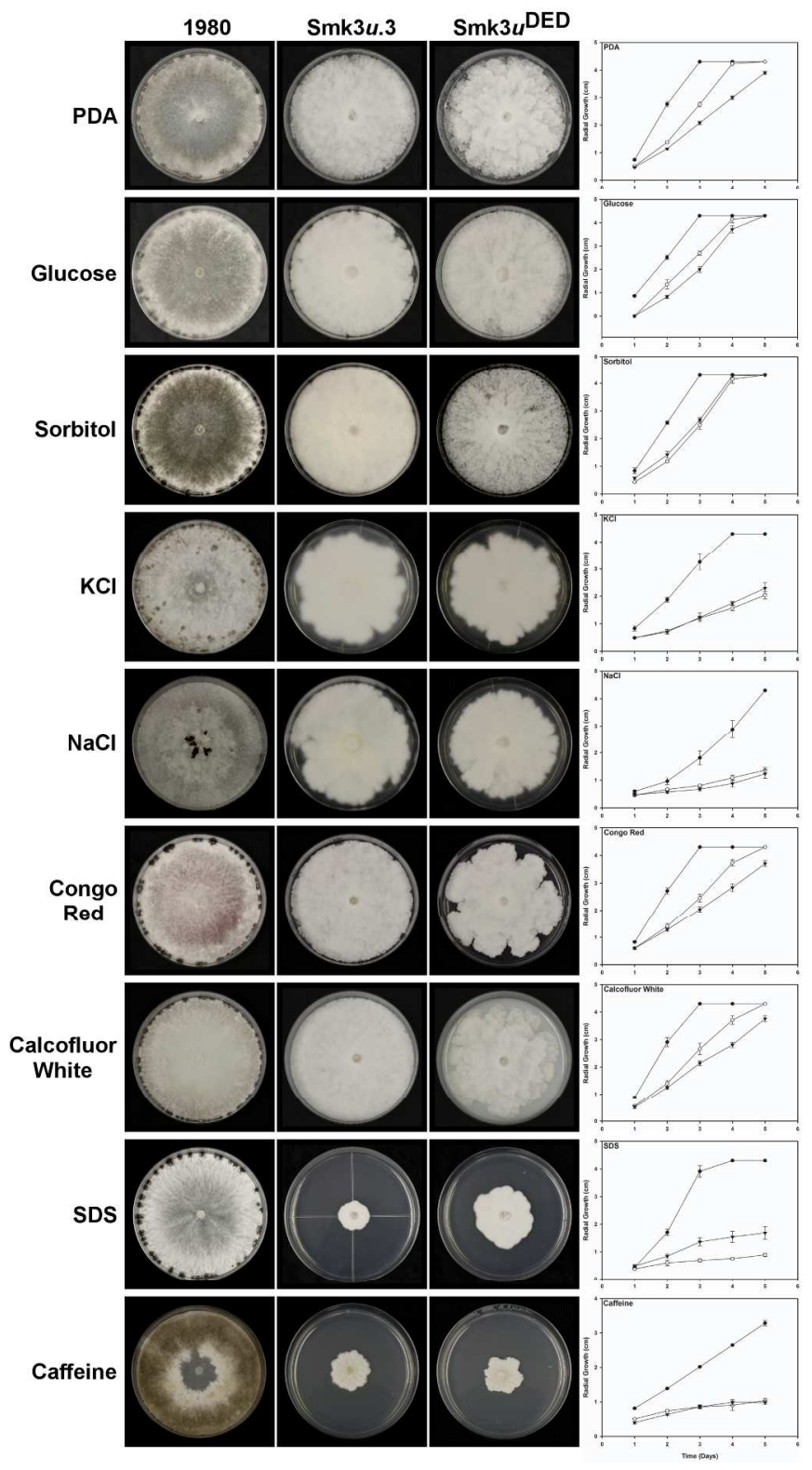

$154 \times 282 \mathrm{~mm}(300 \times 300 \mathrm{DPI})$ 


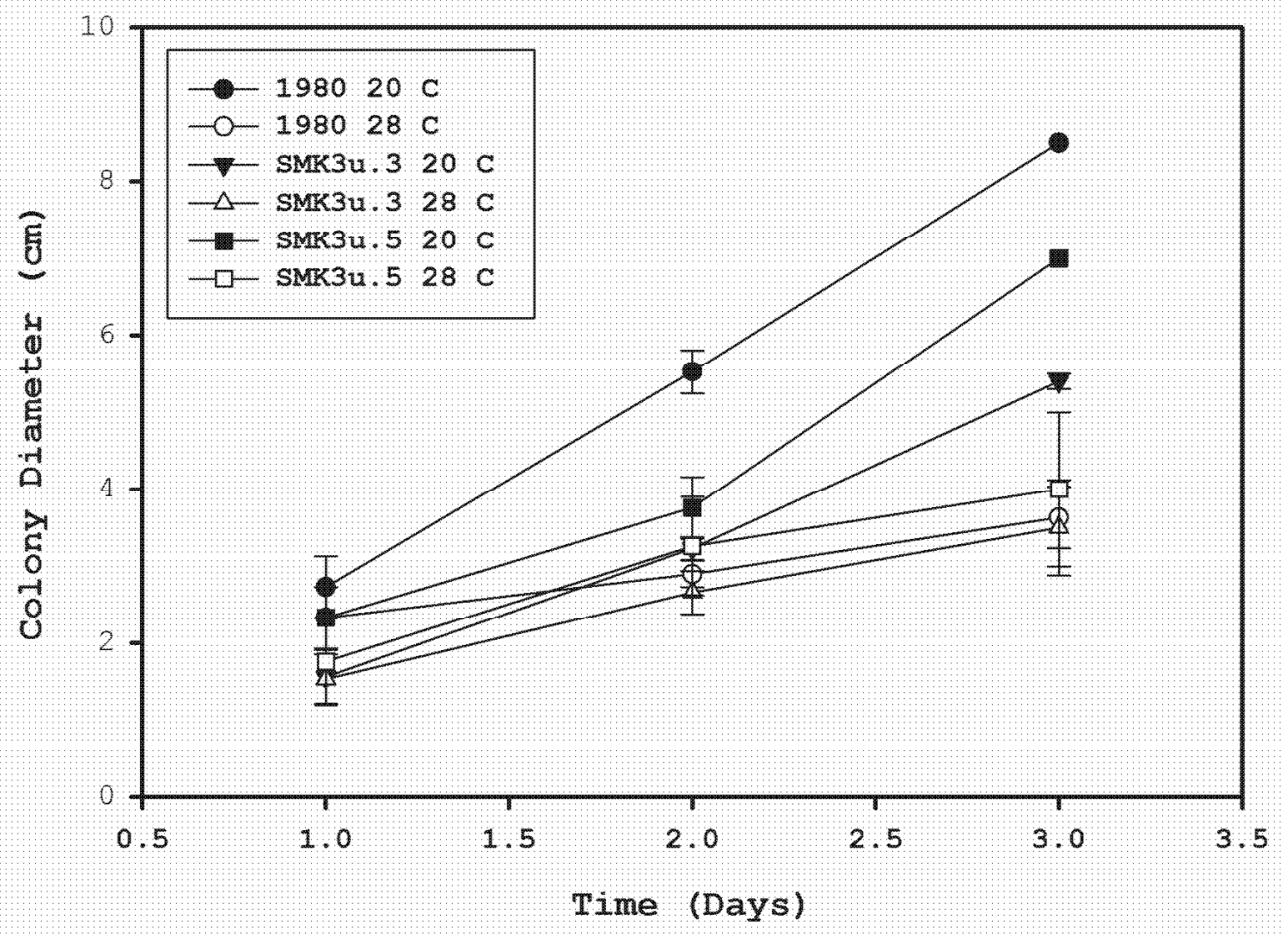

Figure 7

$150 \times 131 \mathrm{~mm}(300 \times 300 \mathrm{DPI})$ 


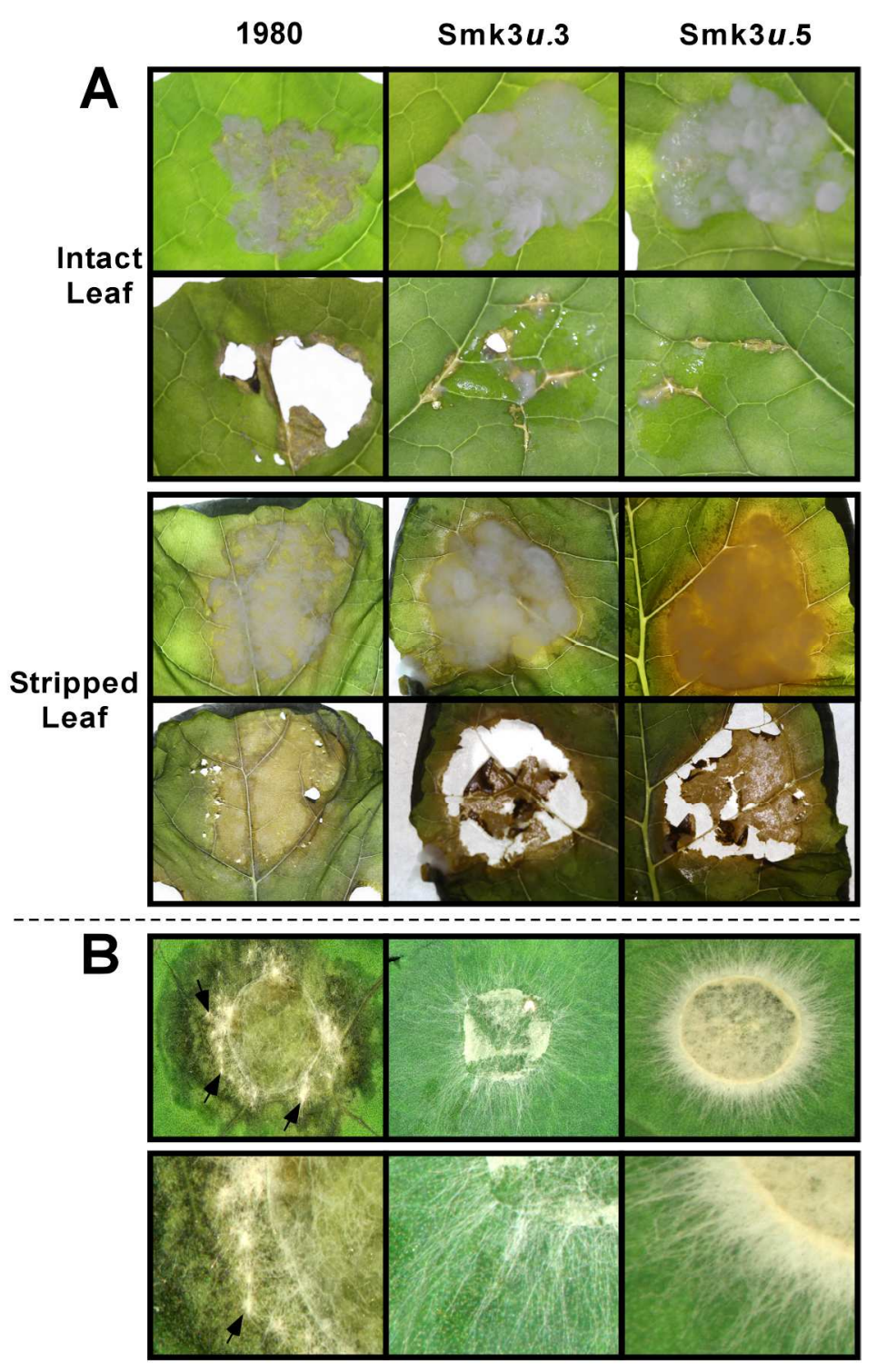

Figure 8

$169 \times 263 \mathrm{~mm}(300 \times 300 \mathrm{DPI})$ 